\title{
OBSERVACIONES A "INCONSTITUCIONALIDAD Y DEROGACIÓN"
}

\author{
Ulises Schmill O.
}

ITAM, México

\section{Introducción.}

En el ensayo denominado Inconstitucionalidad y Derogación, Claudina ORUNESU, Jorge L. RODRíGUEZ y Germán SUCAR (en adelante ORS) analizan varios temas de gran importancia teórica, todos los cuales no pueden ser tratados en una réplica como la que se intenta en estas páginas. Debo confesar desde el inicio que en el tratamiento de muchos de los temas estoy de acuerdo, pero discreparé esencialmente en otros, por el hecho de que mi concepción del derecho es estrictamente positivista. Por ello, de entre ellos, escogeré para comentarlos, los que me parecen más importantes, porque se refieren a una concepción central sobre el orden jurídico. Los temas que se analizarán en esta réplica son los siguientes:

1. Presentaré mi propia versión y crítica de la "cláusula alternativa tácita", que difiere parcialmente de la sustentada por los autores del ensayo que comento; 2. Defenderé la tesis de que la const-inconstitucionalidad no es algo "dado", pues debe estar establecida de manera positiva por la decisión de un órgano jurídico;

3. Por ello, intentaré demostrar la imposibilidad de considerar que existen constinconstitucionalidades a priori;

4. Se harán algunas observaciones críticas sobre los conceptos de norma y sistema jurídico;

5. Presentaré una posible reconstrucción teórica del orden jurídico, que será el fundamento para presentar los conceptos de la derogación y de la anulación condicionada, entendidas como modalidades del ámbito temporal de las normas jurídicas;

6. Expondré la tesis de que la derrotabilidad es anulabilidad condicionada, entre otros motivos, por inconstitucionalidad;

7. Por último, expondré lo que en mi opinión es la omisión fundamental en el ensayo que se comenta, que es la relación esencial entre los conceptos de la regularidad y los de anulación y los sujetos que la establecen. 


\section{Nueva exposición de la "cláusula alternativa tácita"}

Los autores cuyo trabajo comento afirman desde el inicio que

Para la teoría del derecho siempre ha representado un problema el status de las normas inconstitucionales... Ahora bien, las normas inconstitucionales son inválidas, esto es, no satisfacen todas las condiciones que permiten predicar "validez" a su respecto... No obstante lo dicho, las normas inconstitucionales muchas veces producen efectos jurídicos, al menos en tanto su inconstitucionalidad no haya sido declarada por un órgano del Estado. ¿Cómo es posible entonces explicar que una norma inválida produzca efectos jurídicos? (Ap. 1)

Aquí está planteada con toda nitidez la problemática (y la paradoja que genera) relativa a las normas irregulares. Nadie fue más consciente de estos problemas que el mismo KeLSEN. Los autores transcriben el siguiente párrafo de KELSEN que contiene también la dificultad mencionada:

La afirmación de que una ley válida es "inconstitucional" constituye una contradictio in adjecto. Puesto que una ley sólo puede ser válida fundándose en la constitución. Si hay alguna razón para suponer que es válida, el fundamento de su validez se encuentra en la constitución. De una ley inválida no podría sostenerse que es inconstitucional, puesto que ley inválida no es ley alguna, siendo jurídicamente inexistente, sin que sobre ella sea posible formular ningún enunciado jurídico. ${ }^{1}$

Sin embargo, KelSEN sabía que, en ocasiones, mejor, siempre, sobre las Ilamadas "leyes inconstitucionales", pueden llevarse a cabo, y de hecho se llevan, procedimientos jurídicos para el análisis de su constitucionalidad y para su anulación eventual y que, en general, son consideradas válidas, aunque se afirme que ha existido irregularidad en el proceso de su creación o se encuentran en contradicción con los contenidos establecidos en la constitución, es decir, si no cumplen con los requisitos constitucionales para ser consideradas válidas formal y materialmente, para usar la terminología de R. GUASTINI que se cita en el texto. Para salir de esta dificultad, KeLSEN postuló su tesis de la "cláusula alternativa tácita", justamente criticada. En el texto del ensayo que se comenta se contienen algunas refutaciones certeras sobre esta cláusula alternativa tácita, las que no repetiré en este lugar. Sin embargo, sí quiero hacer la observación de que, en mi opinión, KELSEN se vio conducido a postular tal cláusula porque identifica tres conceptos diferentes: el de validez, el de existencia y el de regularidad (o 
legitimidad) de las normas. La tesis de KELSEN puede presentarse de la siguiente manera:

$$
\text { Validez }=\text { existencia }=\text { regularidad }
$$

Si la identidad (1) se acepta, entonces sólo pueden considerarse válidas las normas regulares; si hay irregularidad, las normas no son válidas y, por tanto, son inexistentes. Una norma irregular es una norma inválida, y esto significa que no es norma alguna, por lo que afirmar su existencia o validez es una contradictio in adjecto. Pero como tales normas irregulares producen efectos jurídicos, como lo observan ORS debe conciliarse u ocultarse la irregularidad, pagando un precio muy alto: la norma superior que la determina contiene tácitamente una cláusula alternativa. $^{2}$

Aquí existe un dilema: si la norma es irregular, no existe como norma y si, por el contrario, existe como norma, entonces necesariamente es regular, es decir, es válida. Sin embargo, hay un hecho innegable, expresamente admitido por KeLSEN: la existencia de normas irregulares, de normas que se han dictado o establecido con alguna irregularidad en cualquiera de los actos normados por la norma superior o con un contenido incompatible con el determinado por dicha norma superior. A pesar de ello, la norma existe y puede ser objeto de control de su constitucionalidad por medio del juicio que se tramite ante una corte de constitucionalidad, por mencionar uno de los medios posibles de control de la constitucionalidad. Se trata de una norma irregular y, además, válida. La admisión de la existencia de una norma irregular presupone que el orden jurídico no es unitario, que no forma un sistema, sino contiene normas contradictorias, tesis que Kelsen no admite. Ante este dilema, Kelsen asume una posición teórica verdaderamente heroica: no renuncia a ninguna de sus tesis, pero formula el sentido de las normas que establecen facultades, en especial, la constitución, como normas que tienen carácter alternativo, que contienen tácitamente una cláusula de alternatividad. Ya desde 1934, con la publicación de la TPD1, ofrece esta solución al problema planteado, diciendo:

Si es posible una ley inconstitucional, es decir, una ley válida que contradice las prescripciones de la constitución vigente, bien por el modo de haberse aprobado, bien por su contenido, ese estado de cosas no puede interpretarse sino de este modo: que la constitución no sólo quiere la validez de la ley constitucional, sino también (en cierto sentido( la validez de la ley "inconstitucional"; de otra manera, no podría hablarse de una "validez" de la última. El que la constitución quiera también la validez de la llamada ley inconstitucional, surge del hecho de que ella prescribe, no solamente que las leyes deben ser producidas en una forma 
determinada y que deben tener o no tener un contenido determinado, sino también que, en caso de ser producida una ley en otra forma que la prescripta o tener otro contenido que el prescripto, de ningún modo ha de considerarse nula, sino que ha de valer hasta tanto sea anulada por una instancia destinada para ello, acaso por un tribunal constitucional, en un procedimiento regulado por la constitución... Tiene más importancia el hecho de que la mayor parte de las constituciones no prevean en general una derogación de las leyes inconstitucionales, y se contenten con la posibilidad de hacer personalmente responsables a ciertos órganos, por ejemplo, al jefe de Estado o al ministro, a raíz de la aprobación de la ley inconstitucional, sin que por ello sea además alcanzada la validez de la misma. Lo que se llama "inconstitucionalidad" de la ley no es, por tanto, una contradicción lógica en que se encuentre el contenido de una ley con el contenido de la constitución, sino una condición estatuida por la constitución para la iniciación de un procedimiento que conduce, o a la derogación de la ley (hasta entonces válida y por ende constitucional/, o al castigo de un órgano determinado. Los preceptos de la constitución concernientes a la producción y el contenido de las leyes, sólo pueden ser comprendidos en conexión esencial con aquellos que se refieren a la "violación" de la constitución, es decir, a las normas creadas en forma distinta de la previamente prescripta, o que tienen un contenido distinto del previamente prescripto. Considerados desde este punto de vista, ambos preceptos forman una unidad. Las prescripciones concernientes a la legislación ofrecen, de acuerdo con esto, el carácter de prescripciones alternativas, en las que se atribuye el mismo valor, sin embargo, a ambos miembros de la alternativa. La diferenciación tiene lugar en el sentido de una descalificación de la segunda alternativa frente a la primera. Y esta descalificación se traduce en el hecho de que es la ley correspondiente al segundo y no al primer precepto de la alternativa, aquella que en virtud de su calificación es declarada anulable por la constitución, o por causa de la cual un órgano es declarado punible. En el hecho de que la norma "antinormativa" pueda ser suprimida o de que un órgano deba ser castigado por su causa, reside aquello que se designa, mejor que con la expresión "antinormatividad" ("inconstitucionalidad", "ilegalidad"), con la "deficiencia" o "defectuosidad" de la norma. ${ }^{3}$

Estamos frente a dos tesis, ninguna de las cuales es, en principio, aceptable: o se acepta que el orden jurídico es un orden que admite contradicciones, que no forma una unidad lógica consistente, o se acepta la tesis kelseniana de la cláusula alternativa tácita, con lo que se salva la unidad del orden jurídico. Como ya se dijo, esto es incompatible con su esfuerzo de considerar al orden jurídico como un orden que no contiene contradicciones entre normas de diferente grado. ${ }^{4}$ La concepción de las normas que establecen facultades como normas alternativas destruye el significado normativo de las mismas, porque las convierte en 
tautologías: la norma establece el proceso de creación y el contenido de las normas que van a ser creadas y con ello, "quiere" la validez de las normas regulares, pero también "quiere" que las normas sean creadas siguiendo otro procedimiento y con un contenido distinto del establecido por la norma condicionante, es decir, "quiere" la validez de las normas irregulares. Por tanto, el contenido de la norma es A o no A, lo cual no es normar conducta alguna. La tesis es: la norma para existir, i.e., para ser válida tiene que ser regular. Hay normas válidas irregulares; por lo tanto, hay que reformular la norma condicionante superior, permitiendo la validez de las normas irregulares, en relación con la primera alternativa de manera que no haya norma alguna válida que sea irregular, por concordar con la segunda alternativa. Con la tesis de la cláusula alternativa se trasmuta alquímicamente la irregularidad de la norma en regularidad de la misma. Si no formulara KeLSEN a la norma superior como una norma alternativa, entonces tendría que reconocer que las normas irregulares no son normas, por la identidad expresada en (1), poniéndose en contradicción con el hecho de que existen normas que son válidas y, posteriormente, son declaradas irregulares por el órgano competente para ello. Su experiencia como miembro de la Corte Constitucional Austriaca claramente le mostró la existencia de normas irregulares.

El carácter alternativo de la norma superior determinante de la inferior, excluye la posibilidad de que la norma inferior aparezca en contradicción lógica efectiva con la superior; pues una contradicción con el primero de los preceptos alternativos en que se divide la norma integral de grado superior, no es una contradicción con la norma integral alternativamente configurada. Y aun la contradicción de la norma de grado inferior que ha de examinarse en el procedimiento previamente prescripto, con el primero de los preceptos alternativos de la norma de grado superior, sólo se manifiesta después de ser verificada por la instancia competente. La "contradicción" aparece en la esfera del Derecho, pero simultáneamente con la derogación de la norma contradictoria. ${ }^{5}$

Como puede verse de la anterior trascripción, la cláusula alternativa tácita surge con el objeto de preservar la concepción del Derecho como un orden unitario de normas, en el cual no se da contradicción alguna entre norma de diverso grado normativo. Con cláusula alternativa, la "antinormatividad" de una norma se convierte en regularidad de la norma. Si la norma de grado inferior concuerda con la primera alternativa de la norma superior, es regular, es válida y existe como norma; si no concuerda con la primera alternativa, es entonces regular con la segunda alternativa, hasta que no sea nulificada por el órgano competente, caso en el cual ya no hay norma de la cual predicar irregularidad alguna. 
Si quieren evitarse estos trucos de magia lógica, entonces es necesario reconocer que la existencia de la norma es distinta de su regularidad, que existen normas jurídicas que pueden ser declaradas irregulares y, por tanto, anulables. Volveremos sobre este tema más adelante.

La casi totalidad de los argumentos anteriores se encuentran consignados en el ensayo que se comenta. Los autores del ensayo, aceptan la tesis de BuLYGIN sobre las fuentes que llevaron a KELSEN a la aceptación de la cláusula alternativa tácita. Una de esas fuentes, según nuestros autores, es la ambigüedad del término "validez de una norma" y el sentido del enunciado sobre la existencia de una norma. No estoy de acuerdo con estas afirmaciones. En primer lugar, la identidad (1) establecida más arriba, no creo que sea correcto calificarla de ambigua. Podrá no ser correcta, pero no es ambigua, excepto si se quiere distinguir entre los conceptos de existencia de una norma, su validez y su regularidad. Esta necesidad no se presenta dentro de la teoría de Kelsen. Por otra parte, Kelsen no tiene necesidad teórica alguna de distinguir diversos sentidos de la expresión "existencia" de una norma. Lo único importante, para la comprensión de la tesis de KelSEN, es entender o explicitar el sentido de la frase de que la validez es la existencia específica de una norma. ¿En qué consiste esta especificidad de la existencia de una norma? Según mi interpretación, esta especificidad de la existencia de la norma tiene dos elementos conceptuales, que se encuentran sintetizados en la expresión que se analiza:

1. Toda norma es el sentido de un acto determinado de un sujeto dirigido a la conducta de otro sujeto y, por tanto, no existe norma jurídica alguna que no esté asociada a un acto determinado de un sujeto. En esto consiste la positividad del derecho. Esto lo podemos representar de la siguiente manera: $a(n)$, donde a está por el acto del sujeto y $n$ por el sentido subjetivo del acto dirigido a la conducta de otro sujeto. Este elemento se puede asociar con la afirmación de la existencia de una norma entendida como la emisión de una formulación normativa de Butrgin y ORS. Podemos completar el esquema de esta manera: $\mathrm{a} V(\mathrm{n})$, donde a es el acto, $V$ es su carácter verbal y su sentido $n$ es una norma. La formulación normativa es $V(n)$, el conjunto de signos lingüísticos que contienen como sentido una norma.

2. La norma es el producto de una específica abstracción realizada sobre el acto de su emisión, cuyo sentido se expresa mediante el concepto del deber ser, i.e., el sentido o significado tiene carácter normativo. Esta es la especificidad de la que habla KeLSEN. Es el producto de un corte en el esquema mencionado, corte que podemos representar de la siguiente manera: $\mathrm{aV} /(\mathrm{n}) /$; la norma se encuentra representada dentro de las dos barras inclinadas. Lo que 
obtenemos es un elemento puramente semántico.

Por ello, KeLSEN no se encuentra en la necesidad de distinguir diversos sentidos de la existencia de una norma. Los tres elementos que aparecen en el esquema $\mathrm{aV}(\mathrm{n})$ son considerados como una unidad indisoluble, siempre presentes y actuales. (Lo anterior me excusará de hacer consideraciones críticas en relación con los diversos sentidos de la expresión "existencia de una norma", las que nos desviarían de la finalidad fundamental de este trabajo.)

\section{Lo "dado" en el derecho y el carácter constitutivo de los actos jurídicos}

ORS consideran, de acuerdo con tesis de Butrgin, que el otro elemento que determinó en KeLSEN la aceptación de la cláusula alternativa tácita es que "las decisiones judiciales no son meramente declarativas sino que poseerían carácter constitutivo".

Dicen ORS que este punto de vista de KELSEN:

1.es "evidentemente incompatible con sus manifestaciones en torno a la estructura jerárquica de los sistemas jurídicos". (2.3)

2."no es sino el producto de una confusión entre el carácter definitivo de ciertas decisiones y su infalibilidad". "Una decisión puede ser definitiva, en el sentido de que no puede ser cuestionada ante ningún otro órgano $y$, no obstante, ser equivocada". (2.3)

Es de llamar la atención que no dicen en qué sentido resulta incompatible la tesis del carácter constitutivo de las decisiones judiciales con su tesis de la estructura jerárquica de los sistemas jurídicos, aunque esta incompatibilidad les parece evidente. Este es un punto esencial al que dedicaremos algunos párrafos para esclarecer su sentido.

En estas afirmaciones es posible encontrar algunos presupuestos que es necesario poner en claro, hacerlos explícitos, ya que son fundamentales pues se refieren al concepto del derecho y a la función de la ciencia jurídica o jurisprudencia.

Es muy conocida la concepción del derecho como un orden dinámico de la conducta humana, como un conjunto de normas que regulan su propia creación; concepción que, además, permite determinar la pertenencia de una cierta norma a un orden normativo. En el trabajo de los autores que se comenta, existe una terminología ligeramente distinta: hablan de la dinámica jurídica, 
como una ordenación temporal de sistemas jurídicos, constituidos por normas promulgadas y normas deducidas de ellas. Por lo pronto no tocaré este tema, aunque más adelante podré hacer algunos comentarios al respecto. KELSEN, sin embargo, tiene una concepción distinta que es conveniente enfatizar: el orden dinámico de normas es un orden creativo de normas, es un orden que regula la creación de nuevas normas, de manera que puede concebirse como un desarrollo autopoiético, como una producción continua de contenidos que transcurre de lo más general a lo individual y concreto. KeLSEN siempre ha enfatizado esta dimensión creadora de normas. La norma creada de grada inferior no repite el contenido de la norma que la determina, el de la norma que es su fundamento; por el contrario, visto el contenido de la norma inferior, abstraída de los actos de su creación, etc., y comparado con el contenido de la norma condicionante, puede comprobarse que siempre hay un incremento en el contenido, que no hay una relación analítica entre ellos, sino más bien de carácter sintético. Con esto quiero decir que la actividad creadora de normas tiene por función esencial incrementar el contenido normativo que comienza en la constitución, se continúa en las leyes, reglamentos, circulares, disposiciones administrativas y sentencias, todas las cuales colaboran para dotar de significado al último acto de ejecución. Es cierto que en ocasiones la norma de una ley, especialmente si es una ley reglamentaria de algún precepto constitucional, puede repetir en sus primeros artículos algún contenido normativo de la constitución, para fijar la materia de su regulación, pero esta repetición, por estar en una ley, puede generar una serie de fenómenos jurídicos que no es el caso analizar en este lugar. Baste observar que un acto administrativo puede impugnarse por ilegal, en vez de inconstitucional, en caso de que se encuentre en contradicción con la norma contenida en el cuerpo legal y que resultaría competente el tribunal ordinario y no de carácter extraordinario constitucional.

Es sabido que KeLSEN visitó a Hermann COHEN en Marburgo, ${ }^{6}$ de quien tomó la idea de calificar a su teoría con el adjetivo "pura", como Cohen lo había hecho con las tres partes de su sistema filosófico. ${ }^{7}$ Aunque la idea original de concebir al derecho genéticamente fue de Adolf MeRKL, KeLSEN fue quien la desarrolló de manera brillantísima a lo largo de toda su extensa vida científica. Yo no tengo duda que la aceptación de la teoría de la Stufenbau estuvo influida por los fundamentos filosóficos de la "lógica del origen" de CoHen. Conforme esta teoría, sólo es aceptable en un sistema científico aquello que pueda construirse desde su origen, aquello que pueda ser originado con base en ciertas hipótesis. Permítaseme transcribir un párrafo de la primera parte del sistema de la filosofía construido por Hermann COHEN, que trata sobre el problema de lo "dado", que para él tiene el significado de lo construido: 
La expresión "dado" surge en el lenguaje matemático, supuestamente en el método analítico de Platón. Las condiciones para la construcción del problema se llaman dadas. Euclides escribió un libro especial con el título "Los Datos" ( ). Lo que entiende con ello se muestra en la 4. Definición: "Puntos, líneas y espacios se llaman, según la posición, dados, cuando pueden...ser puestos en realidad o pueden ser encontrados". Entonces, cuando pueden ser encontrados se Ilaman también dados. Pueden ser encontrados solamente por el pensamiento; por eso se Ilaman dados. Los datos del análisis se denominan dados...Solamente puede valer como dado al pensamiento lo que él mismo puede encontrar. ${ }^{8}$ (Énfasis añadido por US)

En concordancia con este pensamiento de COHEN, KeLSEN considera que, en la ciencia del derecho, nada debe considerase como dado, sino que todo debe ser construido teóricamente. Pero no sólo en la ciencia del derecho. El derecho mismo es entendido como un orden normativo que se crea y recrea en el tiempo. Este es el sentido de su tesis de la Stufenbau que, como lo ha repetido infinidad de veces, consiste en que las normas sólo existen si han sido creadas por un acto humano específico, i.e., sólo valen como normas positivas. Esto significa que no se puede considerar como dada al orden jurídico norma alguna que no esté asociada a un acto de promulgación, para utilizar esta expresión de los autores cuyo trabajo se comenta. Véase lo que dice en la TGE:

Así como sólo puede haber una naturaleza, y todo cuanto a ella pertenece desde el punto de vista del conocimiento naturalista tiene que ser comprendido en una única síntesis, del mismo modo sólo puede haber un orden jurídico. Desde el punto de vista epistemológico, la unidad del mundo del Derecho es de la misma especie que la unidad de la naturaleza. Y así como desde el punto de vista de la realidad natural tiene que constituir "naturaleza" cuanto es dado a él (es decir, cuanto debe ser determinado según la legalidad específica de ese sistema, la ley de causalidad, y nada hay dado que no pueda determinarse según leyes naturales), y, por tanto, desde ese punto de vista sólo "hay" naturaleza y no puede haber más que naturaleza, del mismo modo, desde el punto de vista jurídico, no hay, no puede haber más que Derecho y sólo puede ser "dado" lo que puede determinarse con arreglo a la propia legalidad específica del Derecho: la ley jurídica. ${ }^{9}$

Conforme a esta tesis, el derecho entendido como un orden que se autogenera conduce a la conclusión que sólo puede ser "dado" como jurídico aquello que puede determinarse conforme a las normas del propio derecho. La lógica del origen coheniana y kelseniana conduce de manera necesaria a la tesis del positivismo, pues sólo puede ser dado al derecho aquello que se ha generado, aquello que ha sido puesto o establecido por medio de un acto humano. 
Esta concepción tiene profundas consecuencias para el entendimiento de la manera como funciona el derecho, de la forma como opera y de los elementos que pueden considerarse como pertenecientes a él. Igualmente determina el concepto de la ciencia jurídica.

\section{No hay const- inconstitucionalidades a priori}

Veamos ahora cuáles son las consecuencias de estas posturas filosóficas, que se encuentran en la base de la teoría jurídica, como uno de sus presupuestos. KeLSEN fue inconsecuente con su propia teoría. Cuando afirma que una ley inconstitucional es una contradictio in adjecto, se olvida que la inconstitucionalidad de una norma, la "antinormatividad" de ella, no es algo que se encuentre "dado" con la sola emisión de la norma. La inconstitucionalidad debe ser establecida, producida, constituida con los medios y métodos propios del derecho, entendido como un orden dinámico de normas. La inconstitucionalidad de una ley o norma general o de un acto sólo estará "dada" a la ciencia jurídica si es capaz de comprobar que se han cumplido los requisitos y condiciones establecidos por el propio derecho comprendido como un orden dinámico de normas. Esto quiere decir que la inconstitucionalidad no está "dada" a priori, desde la fecha de emisión de la norma a la que cual se califica con ese adjetivo jurídico, pues la inconstitucionalidad debe ser establecida de manera positiva, debe estar constituida en el proceso de progresiva individualización del orden jurídico. Esto que parece muy filosófico y alejado de la realidad es lo más empírico que puede afirmarse. Veamos. Se emite una ley por el Congreso o el Parlamento. Se publica en el Periódico Oficial y entra en vigor a partir del día siguiente a su publicación. ¿Puede afirmarse su inconstitucionalidad? ¿Es ella constitucional o inconstitucional? Lo más talentosos y eruditos profesores tienen opiniones sobre ello: algunos dicen que sí es inconstitucional mientras otros lo niegan y ambos bandos dan argumentos muy sesudos, inteligentes, eruditos para afirmar la propia tesis. La ley comienza a aplicarse. Es, por tanto, una ley existente y una ley válida, en el sentido de que se ha convertido en el fundamento normativo de actos de ejecución de la misma. Hasta el momento, los órganos que la aplican han examinado su validez y decidido que deben obedecerla y ejecutarla y, con base en ella, han emitido otras normas, reglamentarias e individuales, como, por Ej., resoluciones administrativas de gran importancia y trascendencia social y económica.

El problema específicamente jurídico de si un determinado acto es un acto jurídico, no es uno que consista meramente en una subsunción lógica. Lo que importa es una decisión, una decisión jurídicamente obligatoria, auténtica, constitutiva, a la que el orden jurídico enlaza una determinada consecuencia. Una decisión tal no 
es una mera función de la razón, sino de la voluntad; y por ello, ni la ciencia del derecho ni cualquier otra ciencia es competente para tomar esta decisión. Tomar una decisión jurídicamente obligatoria significa establecer una norma (individual). La ciencia jurídica, en tanto ciencia, no puede crear normas. Ella puede solamente describir y reproducir descriptivamente a las normas que han sido creadas por los órganos jurídicos en procesos jurídicos. ${ }^{10}$

Alguno dirá que esto es una afirmación de la última etapa irracionalista de Kelsen. No lo creo así. Conforme al concepto del derecho entendido como un orden dinámico de la conducta humana se tiene que afirmar que esa ley, por lo menos, existe y es válida y hasta el momento, en el tiempo presente, los órganos del Estado competentes para aplicarla y ejecutarla lo han considerado así. Para ellos, en sus actos, han determinado que la norma existe y es válida, lo que puede (pero no tiene que) implicar que consideran que es una norma regular. La constitucionalidad de una norma es constituida por el órgano jurídico y sólo así esta "dada" jurídicamente, i.e., existe para el derecho. Lo mismo puede decirse de la inconstitucionalidad. La trascripción del siguiente párrafo de KeLSEN expresa con toda claridad los conceptos anteriores, lo cual se encuentra en directa contradicción con las tesis que se afirman en el trabajo que se comenta, en el cual se sostiene la inconstitucionalidad a priori de las normas, incluso después de que el órgano jurídico competente último, como la Corte suprema, ha determinado con la calidad de cosa juzgada, la constitucionalidad o inconstitucionalidad de ley en cuestión.

Cuando el Congreso de Estados Unidos aprueba una ley, cualquiera puede externar su opinión si la ley es constitucional, i.e., si es una norma obligatoria o no lo es. Tales opiniones externadas son jurídicamente irrelevantes, pues el orden jurídico no enlaza a ellas ninguna consecuencia. Sin embargo, cuando una ley aprobada por el Congreso va a ser aplicada por un juez, conforme a su criterio, en un proceso judicial, y si el juez es de la opinión de que la ley es inconstitucional, que la decisión del Congreso no es, en otras palabras, legalmente obligatoria, entonces el juez, de conformidad con el orden jurídico vigente, debe abstenerse de aplicar la ley aprobada por el Congreso que tiene la pretensión subjetiva de ser una ley. El juez decidirá el caso sometido a su consideración como si la ley nunca hubiera sido aprobada, como si no hubiera existido. Sólo si el juez es de la opinión de que la decisión del Congreso es constitucional, que es un ley obligatoria, la aplicará al caso en cuestión. La opinión del juez relativa a la regularidad o irregularidad constitucional de la decisión del Congreso y, esto significa, la opinión relativa al carácter jurídico del acto, no es un mera subsunción lógica de un estado de cosas concreto bajo un concepto abstracto, no es una operación intelectual que cualquiera puede realizar, como también lo puede hacer la razón de la ciencia jurídica, sino una decisión que sólo el juez es competente para tomar y a la cual 
el orden jurídico enlaza consecuencias de la más grande importancia.

La esencia del orden jurídico consiste en enlazar a ciertos hechos, como condiciones, determinadas consecuencias. Sin embargo, cuando el orden jurídico, de manera general, enlaza a ciertos hechos, como condiciones, determinadas consecuencias, de manera necesaria debe prescribir también cómo debe comprobarse auténticamente la existencia del hecho condicionante en un caso concreto, para que la consecuencia estatuida pueda ser realizada. Por ello, no son los hechos en sí a los que están enlazadas las consecuencias jurídicas, sino a la determinación constitutiva de los hechos dentro de un procedimiento jurídico. Es inevitable, por tanto, la determinación, en un procedimiento regular, de los hechos condicionantes. Cuando el hecho condicionante es un acto jurídico, entonces tiene siempre y en todas las circunstancias que ser determinada la existencia de este acto jurídico en un procedimiento jurídico, es decir, por un órgano jurídico. De esta manera tiene que ser decidido si el acto en cuestión es un acto jurídico, si es precisamente ese acto uno al que el orden jurídico enlaza consecuencias. Esto significa, empero, que el órgano jurídico que ha de llevar a cabo la consecuencia, debe comprobar siempre y en todas las circunstancias, si el acto en cuestión es un acto jurídico, incluso si el orden jurídico contiene prescripciones, de las que de manera inexacta se dice, excluyen el derecho de examen. Si la constitución determina que los tribunales deben aplicar las leyes que ha dictado el Parlamento, puede, de seguro, también especificar que la regularidad constitucional de esas leyes no puede ser examinada por los tribunales. Pero ella no puede prohibir que el tribunal examine si algo, que se presenta subjetivamente como una ley, ha sido aprobada por el Parlamento y no por una asociación privada. El orden jurídico puede prohibir a los tribunales ordinarios revisar la regularidad jurídica de un acto administrativo, reservando tal examen a un órgano específico, por ejemplo, un tribunal administrativo. Pero el orden jurídico no puede impedir a los tribunales ordinarios examinar si un acto, que constituye un supuesto de su decisión, es en verdad un acto administrativo, es decir, si ha sido establecido por un funcionario administrativo y no por una persona privada. ${ }^{11}$

Creo que las tesis anteriores son enteramente correctas, sólo bajo el supuesto que el orden jurídico sea un orden dinámico de normas. No son otra cosa que la aplicación consecuente de este concepto del derecho. Por tanto, las decisiones judiciales son constitutivas y esto evidentemente es compatible con la estructura jerárquica de los órdenes jurídicos, lo cual es una tesis contraria a lo afirmado por nuestros autores. Creo incorrectas las tesis contenidas en el ensayo que se comenta en el sentido que la constitucionalidad o inconstitucionalidad de una ley están "dadas" desde el principio y son una mera consecuencia lógica de la comparación del contenido de la ley con el contenido de la constitución. Bajo ningún supuesto estos calificativos pueden considerase como "dados" y, menos aún, con validez jurídica. Todavía es menos aceptable la afirmación de 
que la ley es inconstitucional, incluso si el órgano límite jurisdiccional ha determinado con la calidad de cosa juzgada que la norma es constitucional. Esto simplemente suena a ideología de abogado o al intento de origen iusnaturalista de los juristas de querer influir políticamente en la vida pública del Estado. Lo que no puede afirmarse válidamente es que la ley debe calificarse de modo distinto como lo ha determinado objetivamente la Suprema Corte de Justicia. No aceptar esto supone afirmar la existencia absoluta del criterio de constitucionalidad, con carácter puramente lógico, desconectado del proceso jurídico constitutivo.

Lo único que creo puede afirmarse con certeza es que la ley dictada es un problema, es una incógnita en cuanto a su const- inconstitucionalidad. Podemos afirmar que existe, pues éste es un hecho empírico: basta tan sólo comprobar que ha existido un acto creador de un significado normativo o empleando la terminología de los autores cuyo ensayo se comenta, existe una formulación normativa susceptible de interpretación, sin que pueda afirmarse ni su conformidad ni su falta de conformidad con la constitución. Para decirlo en una palabra, no está dada jurídicamente la const- inconstitucionalidad de la norma, pues ella debe ser establecida o construida normativamente por los órganos jurídicos, para que la ciencia del derecho pueda determinar su carácter en el sentido indicado.

Con lo anterior no se niega la importancia práctica que pueden tener los argumentos privados no oficiales de const- inconstitucionalidad, los cuales pueden llegar a convertirse en el contenido de la decisión del órgano competente para establecerlo, que es la manera como influyen en los procesos jurídicos las doctrinas sobre el derecho. ${ }^{12}$

Contra esto debe observarse que es problemático el supuesto de que la persona que realiza el acto en un caso concreto ha sobrepasado su competencia, y es problemático si el otro supuesto es correcto, de que el acto es considerado acto jurídico obligatorio en el procedimiento jurídico subsecuente por los órganos competentes. ¿Desde qué punto de vista las personas en cuestión han sobrepasado su competencia? Conforme a una prescripción de la Constitución de los Estados Unidos puede el Presidente, con la aprobación del Senado, concluir tratados internacionales. De hecho, el Presidente ha concluido muchos tratados de gran importancia política sin la aprobación del Senado, y estos tratados han sido ejecutados sin reservas por los órganos de los Estados Unidos. ¿Puede decirse jurídicamente, que el Presidente ha sobrepasado su competencia? ¿Es tal juicio, si es hecho por una persona que escribe sobre el derecho, algo distinto de una interpretación jurídicamente irrelevante de la Constitución americana, que se encuentra en oposición a la interpretación legalmente relevante hecha por el 
Presidente mismo, que está facultado para aplicar la Constitución y, por tanto, también para interpretarla? ¿No es jurídicamente un sinsentido, bajo tales circunstancias, afirmar que el Presidente ha sobrepasado su competencia, cuando incluso la Suprema Corte no ha declarado constitucionales ciertos tratados concluidos por el Presidente sin la aprobación del Senado? ¿Cómo puede un acto ser considerado obligatorio en el procedimiento subsiguiente por los órganos jurídicos si al mismo tiempo se le considera ilegal por ser un acto de un órgano incompetente? ¿Y cómo podrían estos órganos considerar el acto, de otra manera que con base en el orden jurídico, como obligatorio, esto es, considerarse a sí mismos jurídicamente obligados a realizar las consecuencias que están enlazadas al acto por el orden jurídico? Los órganos administrativos y los tribunales de los Estados Unidos, en tanto que ejecutan tratados que han sido concluidos por el Presidente sin la aprobación del Senado, deciden que estos actos son actos jurídicos obligatorios, que no son nulos; y esto significa que los órganos administrativos y los tribunales aceptan la interpretación de la Constitución, que subyace en la del Presidente mismo en su función de órgano competente para celebrar tratados. No es posible afirmar en estas circunstancias que los actos en cuestión originalmente se encontraban fuera del orden jurídico y que fueron incorporados al orden jurídico en el procedimiento jurídico subsecuente. Pero, incluso, si la descripción de este proceso fuera correcta, la subsecuente cualificación como actos de un órgano jurídico sería posible solamente con base en el orden jurídico en el cual los actos en cuestión son incorporados. La descripción del proceso por el que es decidido el carácter jurídico de un acto por los órganos legales en el proceso jurídico subsecuente (no por la teoría jurídica o cualquier otra disciplina(, se encuentra estrictamente en el marco de la ciencia jurídica, como un conocimiento dirigido al orden jurídico como un sistema normativo. ${ }^{13}$

Por ello, no resulta aceptable la tesis de los autores argentinos que se comenta en el sentido de que hay una lamentable confusión entre la definitividad de una decisión y su corrección. Aquí está en juego el concepto de la ciencia jurídica que se tenga: o como ciencia descriptiva, cuya principal función es describir qué es y cómo opera de manera efectiva y real el derecho, describiendo las interpretaciones que con validez jurídica hacen los órganos del Estado de las normas positivas en vigor, o como ciencia normativa, cuya función es determinar lo que es lo correcto y verdadero jurídicamente y opera como criterio valorativo (generalmente reprobatorio y crítico) de la actuación de los órganos jurídicos.

\section{Norma jurídica y sistema jurídico}

Sé que me pongo en oposición con una postura teórica que ha adquirido carta de ciudadanía en los círculos académicos de Latinoamérica y otras partes del mundo, por la influencia decisiva que el pensamiento de AlCHOURRÓN y BuLYGIN 
ha ejercido. No niego su importancia, pero debo confesar que las distinciones entre norma jurídica y formulación normativa, aunque permite hacer algunas distinciones útiles, no debe tomársela como un dogma y realizar investigaciones con base en esa distinción. En el apartado 3 del ensayo que se comenta se establecen cuatro distintas concepciones de las normas jurídicas: la concepción sintáctica, la semántica, la mixta sintáctico-semántica y, por último, la concepción pragmática. Estas distinciones pueden utilizarse, si se quiere, para efectos expositivos cuando se quiere hacer énfasis en algún aspecto de las normas jurídicas, pero no puedo aceptarlas como distintas concepciones de las normas jurídicas. Éstas son un complejo de elementos que pueden analizarse desde esos diversos puntos de vista, cuando se quiere enfatizar una dimensión en particular de ese complejo de elementos en que consisten las normas. Anteriormente, presentamos el esquema $\mathrm{a} V(\mathrm{n})$, el cual pone de manifiesto ese complejo de la siguiente manera: a está por el acto creador de la norma, por tanto por su dimensión pragmática; $V$ es el aspecto lingüístico de la norma, por lo tanto, por su dimensión sintáctica y $(n)$ por el significado de la formulación lingüística, por tanto, por su dimensión semántica. La concepción mixta surgiría en el momento en que se consideran conjuntamente la dimensión sintáctica y la semántica, i.e., $\mathrm{V}(\mathrm{n})$. Es un error considerarlas de manera separada; por ello no coincidimos cuando los autores del ensayo que comentamos analizan "La inconstitucionalidad de las normas como formulaciones no interpretadas" pues si con ello quieren referirse al elemento lingüístico puro $V$ de nuestro esquema, nada se puede predicar en verdad de ello, en cuanto a su inconstitucionalidad, pues una formulación verbal o lingüística no puede estar en contra o violar las normas constitucionales. En el apartado 3.2 los autores cuyo trabajo comentamos dicen:

Veamos primero en qué sentido puede decirse que una norma inconstitucional existe, si por ella se entiende la formulación normativa no interpretada que ha sido creada irregularmente por falta de satisfacción de los requisitos impuestos para ello por normas contenidas en la constitución.

Afirman a continuación, para resolver el enigma planteado:

El calificativo de "inconstitucional" asignado a una norma así concebida sólo podría aludir a un vicio formal relativo al acto de su promulgación por parte de un órgano incompetente o por un procedimiento impropio (inconstitucionalidad formal). Dado que se entiende aquí por "norma" a un simple texto normativo sin adentrarse a considerar su significado, y dado que no hay relaciones lógicas entre entidades semejantes, la evaluación de la compatibilidad lógica de dicho texto con las interpretaciones que se atribuyan a los textos constitucionales sólo podría cumplirse en una etapa posterior, de modo que no cabría predicar de tales entidades ni validez ni invalidez desde el punto de vista material. 
Dificultades que pueden evitarse, derivadas de complicadas sutilezas que no es necesario hacer. Nadie, que yo sepa, atribuye inconstitucionalidad formal o material a un simple texto lingüístico. Incluso, nuestros autores no la atribuyen al texto, sino al acto de su emisión, lo cual es algo bien distinto. Que las normas legales son formulaciones lingüísticas, no cabe duda alguna, pues el lenguaje es el medio más común de presentación de las normas jurídicas. Como éstas son el sentido o el significado de formulaciones lingüísticas, dicho sentido o significado debe atribuírsele por interpretación a las formulaciones lingüísticas. Si alguna lección hemos de sacar de aquí, es que las normas se nos presentan generalmente de manera lingüística y no se conoce de antemano cuál es el sentido que puedan adquirir por interpretación. Por cierto, caben distintas interpretaciones a un mismo texto, como es de sobra conocido, por lo que dada una formulación normativa no es posible decir si es o no constitucional o inconstitucional. A priori no es posible predicar ninguno de esos adjetivos respecto de la ley. La ley, como formulación normativa, tal como aparece por vez primera, es más bien algo por determinar, es una incógnita que hay que despejar, para emplear una metáfora de las matemáticas. Por tanto, no es factible (ni posible) aplicar los predicados de constitucionalidad o inconstitucionalidad en este nivel. Lo mismo vale respecto del acto de emisión o promulgación de la formulación normativa, pues su regularidad no está "dada", sino que necesita una serie de investigaciones complicadas, a veces muy difíciles y laboriosas, para determinar si los actos del proceso legislativo se llevaron a cabo con las formalidades y la secuencia que establecen las disposiciones constitucionales. Después de ello, la regularidad con respecto a la constitución puede determinarse en un procedimiento judicial o de otra índole, que culmine en una sentencia o una resolución que determine con validez jurídica la const-inconstitucionalidad de la ley en cuestión. Esta sentencia o resolución, si es tomada por un cuerpo colegiado, como de manera general es el caso, pudo adoptarse con una votación mayoritaria, lo que significa que los titulares del órgano decisorio difieren en su opinión sobre la constinconstitucionalidad. Esto demuestra que la const-inconstitucionalidad no es algo "dado" jurídicamente, de manera indubitable, que sea el resultado de una deducción puramente lógica, sino que es materia de una decisión, de un acto de voluntad, no de un acto de conocimiento. Para no emplear esta terminología psicológica, que KeLSEN utiliza, diremos que la decisión sobre la constinconstitucionalidad es la materia de una norma que la constituye, por medio de los procedimientos y con el método decisorio que generalmente se utiliza en estos cuerpos jurídicos: la votación mayoritaria. Antes de la adopción de la decisión mayoritaria del cuerpo decisorio, no puede afirmarse ni una ni otra cosa. La decisión tiene un carácter claramente constitutivo. Lo que piense y diga el actor o el demandado y, con mayor razón, lo que digan los extraños sobre la 
const-inconstitucionalidad de la ley en cuestión, no constituye la determinación jurídicamente válida de la cuestión planteada.

Todo lo anterior tiene trascendencia sobre un problema que transcurre por la totalidad del ensayo que se comenta: la distinción entre norma y sistema normativo. Esta distinción genera una serie de problemas que simplemente hay que evitar utilizando con energía la navaja de Occam. Contra las tesis sostenidas por nuestros autores cuyo ensayo se comenta y otros autores, no aceptamos la existencia de dos clases de normas: las promulgadas y las deducidas, pues genera una doctrina sincrética respecto de la estructura del derecho. El derecho estaría constituido por normas tanto positivas como por normas no positivas, i.e., deducidas de las promulgadas. Por tanto, no podría aceptarse que el derecho es un orden positivo de normas y esto quiere decir, un orden dinámico de normas. Con ello, la existencia de las normas jurídicas se determina con dos criterios distintos: la positividad y la deducibilidad. Por otra parte, el criterio de la deducibilidad es totalmente impreciso, dependiendo de las reglas de deducción que se acepten, pues es sabido que hay distintos sistemas lógicos, con reglas de deducción diversas, que arrojan resultados diferentes. La derogación de las normas tiene dos principios diversos: hay actos positivos de derogación explícitos y, sin embargo, no hay actos de derogación respecto de las normas deducidas, a menos que se considere que hay una derogación por deducción. Además, la estructura del orden jurídico se complica de manera imposible, pues se considera que hay sistemas momentáneos de normas, cuando a un sistema se le agrega o se quita una norma. Piénsese solamente en el número de contratos de compraventa que se realizan cada día en un país determinado, como México o Argentina. Cada vez que un niño o un ama de casa compra un dulce o una lechuga o un jabón se crea un sistema jurídico distinto. El número de estos sistemas jurídicos momentáneos es caso infinito, pues puede aceptarse que supera los miles de millones al día. No veo la utilidad de este tipo de consideraciones. Por tanto, un orden jurídico como una secuencia de sistemas jurídicos estaría constituido por una cantidad estratosférica de sistemas jurídicos. Por otra parte, ¿el criterio de regularidad sería igual para una norma promulgada que para una norma deducida? La norma deducida existe por lógica exclusivamente, por tanto no puede ser inconstitucional formalmente, sino sólo materialmente.

Lo que nuestros autores denominan "Efectos de la promulgación de normas" y "Efectos de la derogación de normas" son, desde mi punto de vista, solamente posibles interpretaciones de las normas promulgadas o derogadas, interpretaciones que pueden, pero no tienen que coincidir con las interpretaciones con validez jurídica establecidas por los órganos jurídicos. 
En 4.3 dicen nuestros autores lo siguiente:

En primer lugar, como ya se ha señalado, sólo en un sentido impropio puede predicarse inconstitucionalidad de una norma entendida como texto interpretado si el vicio que la provoca es de carácter formal. Ello en razón de que las formulaciones interpretadas no dependen para su existencia de ningún acto de promulgación.

Esto simplemente no me es comprensible. Se supone que existen formulaciones normativas, sin un acto de formulación, lo cual es incluso físicamente imposible. Esta afirmación es el producto de contemplar unilateralmente un complejo de elementos, viendo sólo una cara de ellos. El texto interpretado es texto formulado, de acuerdo con el principio positivista ineludible, que podemos expresar así:

(posit) $n(7) a(n)$

i.e., si existe una norma, entonces esa norma fue establecida por un acto específico.

Por lo anterior, de ninguna manera podemos estar de acuerdo con formulaciones como la siguiente:

Si con la expresión "norma inconstitucional" quiere aludirse a la interpretación de un texto normativo que ha sido promulgado en virtud de un acto formalmente viciado, entonces las normas inconstitucionales así entendidas existen (abstracta e intemporalmente) pero no son parte del derecho. Estas normas pueden asimismo poseer fuerza obligatoria, ser aplicables o eficaces, pero no puede decirse que pertenezcan a ningún sistema del orden jurídico. (4.3)

Francamente dicho, no me es representable una norma inconstitucional que exista, pero que no sea parte del derecho. Por otra parte, estas normas tienen un modo peculiar, muy platónico, de existir, i.e., abstracta e intemporalmente. Desde mi punto de vista, una formulación normativa interpretada puede manejarse de tal manera que solamente se atienda al significado, a la interpretación de la formulación normativa y, es claro que pueden predicarse muchas cosas del producto de esa abstracción, pero lo que no debe hacerse es crear un mundo platónico de entidades etéreas, intemporales y abstractas. En este peculiar y extraño mundo las normas que ahí habitan no pertenecen, me imagino, al 
derecho, entendido como un fenómeno empírico, creado por actos humanos que tienen lugar en el tiempo y en el espacio. Tenemos entonces, que las normas inconstitucionales

1. existen;

2. de manera abstracta e intemporal;

3. poseen fuerza obligatoria;

4. son aplicables o eficaces;

5. pero no pertenecen a ningún sistema del orden jurídico.

Cada cual es libre de representarse los fenómenos como estime más conveniente y verdadero. Yo simplemente manifiesto que no logro representarme una norma jurídica con estas características. Si normas de esta clase no pertenecen a ningún sistema del orden jurídico, tal como lo entienden nuestros autores, entonces no son parte del derecho y, por tanto, no tienen porqué ser estudiadas por la ciencia del derecho o jurisprudencia, pues estaría entonces haciendo afirmaciones sobre un objeto que no pertenece a su objeto de estudio. Simplemente, no sería de su incumbencia afirmar nada sobre ellas, como no es de su incumbencia determinar la función de las oligodendroglias dentro del cerebro. A pesar de ello, i.e., a pesar de no pertenecer al derecho, se afirma que son aplicables y que pueden ser eficaces y, además, que poseen fuerza obligatoria, la cual ha sido definida como la existencia de otra norma que establece la obligación de aplicarlas. A mi modo de ver, la razón de todo este embrollo tiene su origen en que se considera que la inconstitucionalidad está dada a priori, que no requiere de acto alguno de órgano jurídico para constituirla. Supóngase que se emite una ley cualquiera. Si se juzga que es inconstitucional, si se la considera contraria a la constitución, no debe concedérsele validez alguna, en el sentido que se quiera dar a esta palabra tan discutida. Por tanto, no forma parte del orden jurídico, no es parte integrante de ningún sistema jurídico del orden jurídico en cuestión, pues sólo forman parte de él aquellos sistemas que han sido creados conforme a las disposiciones adjetivas y sustantivas de la constitución y sus normas que se consideran que son consecuencias lógicas de las promulgadas. Es claro, además, que estas normas inconstitucionales ab initio, inconstitucionales a priori, han sido formuladas por un órgano con violación de los requisitos formales establecidos en la constitución, por lo que se consideran como normas pero no pertenecientes a ningún sistema jurídico. Pero se observa, para hacer la situación más difícil, que se aplican y que son objeto de consideraciones jurídicas en sentencias creadas por órganos jurídicos. KeLSEN dijo, de manera audaz y casi heroica: es que son normas regulares, porque concuerdan con la cláusula alternativa tácita. Si no acepta esta cláusula, entonces es comprensible que se hagan juicios como los que estamos analizando. 
Las mismas características le atribuyen a las formulaciones normativas interpretadas para el caso en que se encuentre una contradicción lógica o una incompatibilidad lógica con las normas constitucionales. Afirman nuestros autores que los legisladores y los interpretes reaccionan de diversa manera frente a una situación como la indicada.

A fin de solucionar el problema, los legisladores pueden derogar una o las dos disposiciones en conflicto, modificar una de las normas a fin de introducir en ella una excepción en función de lo que la otra dispone, o bien dejar subsistente el conflicto para que sea el eventual interprete o aplicador quien escoja una solución.

En relación con los interpretes, éstos pueden cambiar la interpretación o si esta vía no es posible llevarla a cabo, pueden optar por una de ellas, dejando de lado la otra, haciendo uso de un criterio de preferencia determinado. En primer término, se está analizando el problema del conflicto entre una norma superior y una norma inferior. La solución que se adscribe al legislador es plausible. El interprete se encuentra, según el sentido del orden jurídico, constreñido a preferir a la norma superior, pues es la que le da el criterio de existencia de la norma inferior, pudiéndose afirmar que la lex specialis o la lex posterior, como criterios de preferencia, no se aplican en el caso.

\section{Construcción del concepto del orden jurídico y su sentido}

A efecto de tratar estos problemas con una hipótesis distinta, permítaseme hacer las siguientes consideraciones y presentar algunos esquemas que he elaborado para fijar los conceptos. Presentaré a continuación un procedimiento de construcción del concepto de la facultad jurídica, que nos conducirá a la determinación de la estructura y funcionamiento del orden jurídico. ${ }^{14}$

La siguiente es la estructura general de una norma positiva, como ya lo mostramos más arriba:

$$
a(n)
$$

Debemos ahora llevar a cabo la interiorización en una norma del acto de emisión de la misma. Para ello es necesario considerar el acto de emisión de la norma como el contenido de otra norma, i.e., considerar una norma cuyo contenido sea el acto de emisión de otra norma, convertir en contenido de una norma el acto o los actos de emisión de una o más normas. Esto se logra de la 
siguiente manera:

(3) $\mathrm{V}\{\mathrm{a}(\mathrm{n})\}$

Esta es una formulación verbal o lingüística cuyo contenido es el acto de producción de la norma. Esta formulación verbal la consideraremos como una norma de cierto tipo especial. Por ello, haremos uso del símbolo "!', el cual no forma parte del contenido de la norma, pero indica que se trata de una norma: ${ }^{15}$

$$
! \mathrm{V}\{\mathrm{a}(\mathrm{n})\}
$$

Para hacer más explícito el esquema, el acto de emisión de una norma tiene sus dimensiones de realización personal " $\mathrm{p}$ ", material " $\mathrm{m}$ ", temporal " $\mathrm{t}$ " $\mathrm{y}$ espacial " $\mathrm{e}$ ", por lo que debemos indicarlos como contenido de la norma, lo que los convierte en los ámbitos de validez de la norma:

$$
\text { !V }\{\mathrm{a}(\mathrm{p}, \mathrm{m}, \mathrm{t}, \mathrm{e})\}
$$

Este esquema representa la norma que establece un acto de creación normativa. En él no aparece la norma que va a ser creada por el acto respectivo, por el simple hecho de que se está representando la norma que establece el acto de creación normativa y no a éste último, cuya dimensión material de realización está constituida precisamente por la norma creada por el acto. La situación tendría que representarse de la siguiente manera:

$$
! \bigvee\{a(p, m, t, e)\}-a(p, m(=n), t, e)
$$

Debemos hacer algunas transformaciones adicionales a este esquema: primeramente eliminar el indicador externo de la norma, i.e., eliminar "!", introduciendo un operador que internamente nos permita reconocer que se trata de una norma. Este operador lo simbolizaremos con la letra " $\mathrm{F}$ ", abreviatura de la palabra "Facultad" (Ermächtigung, en alemán y Empowerment, en inglés). Entonces, tenemos:

$$
\mathrm{VF}\{\mathrm{a}(\mathrm{p}, \mathrm{m}, \mathrm{t}, \mathrm{e})\}
$$

La formación verbal anterior es una norma, por lo que la podemos presentar junto con el acto de ejecución de ella, de la siguiente forma:

(F) $\quad n_{1} F\{a(p, m, t, e)\}-a\left(p, m\left(=n_{2}\right), t, e\right)$ 
Con esto tenemos una norma que establece el acto de creación de otra norma y a la función que lleva a cabo esta norma le hemos dado el operador deóntico $F$, al que entendemos como una facultad.

¿Cuál es la interpretación de este esquema? La norma $\mathrm{n}_{1}$ establece en su contenido la facultad o el poder de emitir o crear normas por medio de la realización de un acto específico a, al que determina en sus dimensiones de realización. Con lo anterior hemos construido un orden jurídico, que contiene por lo menos dos normas: la norma $\mathrm{n}_{1} \mathrm{~F}$, que establece la facultad de crear normas y la norma $\mathrm{a}\left(-, \mathrm{m}\left(=\mathrm{n}_{2}\right),-,-\right)$, como el sentido o significado del acto a. Debemos representar el caso en que la norma condicionante o superior determina en su integridad el contenido de la norma condicionada o subsecuente:

$$
n_{1} F\left\{a\left(p, m\left(=n_{2}\right), t, e\right)\right\}-a\left(p, m\left(=n_{2}\right), t, e\right)
$$

Este es el caso de una norma condicionante o superior que delega en un órgano determinado p la creación de una norma específica, indicándole su contenido íntegramente. En vez de que el sujeto emita la norma correspondiente, encarga a otro sujeto, por la razón o circunstancia que se quiera, para que la emita, lo faculta para ello. Es claro que, en muchos casos, la norma que faculta no determina íntegramente el contenido de la norma a emitir por el órgano correspondiente, sino solamente lo instituye como autoridad, dejándolo en libertad para emitir la norma que considere oportuna atendiendo a las circunstancias en las que se encuentre con el destinatario de la segunda norma. Tenemos, entonces, dos normas: la que faculta y la emitida por el órgano facultado, como puede verse en nuestro esquema $\left(\mathrm{F}^{\prime \prime}\right)$ :

$\left(F^{\prime \prime}\right) \quad n_{1} F\left\{a\left(p_{2}, m, t, e\right)\right\}-a\left(p_{2}, m\left(=n_{2}\right), t . e\right)$

En la primera parte, tenemos la norma $\mathrm{n}_{1}$ que faculta al órgano $\mathrm{p}_{2}$ a emitir normas con cualquier contenido, por medio del acto a y determina se lleve a cabo en el tiempo t y en el lugar e. En la segunda parte presentamos el acto a de emisión de la norma $\mathrm{n}_{2}$.

En caso de que el órgano creador de la norma $\mathrm{n}_{1}$ quisiera limitar el contenido de la norma $\mathrm{n}_{2}$ sería necesario que lo especificara dentro de su ámbito material de validez, limitando el contenido posible de la norma dependiente $n_{2}$. En caso de que no exista esta limitación, el órgano $p_{2}$ establecido con esa calidad por la norma $n_{1}$ que lo faculta para emitir las normas representadas como $n_{2^{\prime}}$ está 
en la situación de dar cualquier contenido a la norma $\mathrm{n}_{2}$ que emita. Este caso puede ser representado de la siguiente manera:

$$
\mathrm{n}_{1} \mathrm{~F}\left\{\mathrm{a}\left(\mathrm{p}_{2}, \mathrm{~m}(=\angle), \mathrm{t}, \mathrm{e}\right)\right\}-\mathrm{a}\left(\mathrm{p}_{2^{\prime}} \mathrm{m}\left(=\mathrm{n}_{2}\right), \mathrm{t} . \mathrm{e}\right)
$$

en donde " $\angle$ " está por la ausencia de determinación alguna en cuanto al ámbito material de validez, lo cual significa que el órgano jurídico $p_{2}$ no tiene restricción material alguna al emitir la norma $\mathrm{n}_{2}$, la cual puede tener el contenido que decida darle libremente su órgano creador.

No siempre es el caso que la norma superior o condicionante deje en plena libertad al órgano que instituye para crear la norma, sino que, por el contrario, puede determinar ciertos límites y modalidades al contenido de las normas a crear y es claro que estos límites deben estar consignados en el ámbito material de validez de la norma condicionante o superior $\mathrm{n}_{1}$. Esto se hace, de manera general, con disposiciones muy generales, que admiten diversas interpretaciones, ${ }^{16}$ que acotan de manera amplia, en menor o mayor medida, el contenido de las normas subsecuentes. Estas acotaciones se encuentran en las constituciones modernas que consignan los que se denominan "derechos públicos subjetivos", "garantías individuales y sociales", etc. En el caso de las leyes, la determinación del contenido de las normas condicionadas o inferiores a ellas, es más amplio y detallado, contenido que, a su vez, se incrementa con los reglamentos. Hay tres formas o maneras posibles en que la norma condicionante o superior acota o determina el contenido de la norma condicionada o inferior: el contenido de la norma condicionada puede estar determinado de manera positiva, indicando cuál es el contenido que necesariamente ha de tener o respetar; de manera negativa, indicando el contenido que nunca puede tener, o de manera neutral o potestativa, indicando el contenido que en ciertos casos puede llegar a tener, si así lo decide el órgano creador de la norma subsecuente. En otros términos expresados, la norma condicionante puede determinar el contenido necesario, el contenido excluido o el contenido potestativo de la norma subsecuente. En nuestros esquemas, esto lo podemos representar utilizando el símbolo lógico "L" que representa la modalidad de la necesidad, junto con el símbolo lógico de la negación " ":

$$
\mathrm{n}_{1} \mathrm{~F}\left\{\mathrm{a}\left(\mathrm{p}_{2^{\prime}} \mathrm{m}(\mathrm{z}=\mathrm{Lx} \bullet \mathrm{L} \sim \mathrm{x} \bullet \sim \mathrm{L} \sim \mathrm{x}), \mathrm{t}, \mathrm{e}\right)\right\}-\mathrm{a}\left(\mathrm{p}_{2^{\prime}}, \mathrm{m}\left(=\mathrm{n}_{2}\right)( \pm \mathrm{z}), \mathrm{t}, \mathrm{e}\right)^{17}
$$

En este esquema, en su segundo miembro que representa el acto de ejecución de la norma que aparece en primer término, aparece el símbolo $( \pm z)$, con el que quiero significar que la norma $\mathrm{n}_{2}$ puede estar de acuerdo o en 
discrepancia con el contenido z determinado en cualquiera de las tres formas indicadas en la primera parte de nuestro esquema.

Debemos observar, a continuación, que en los esquemas presentados no necesariamente se contiene solamente un elemento tan simple como (a) realizado por $\mathrm{p}_{2}$. Podemos pensar en esto:

$$
\mathrm{n}_{1} \mathrm{~F}\left\{\mathrm{a}_{2 . \mathrm{r}}\left(\mathrm{p}_{2^{\prime}} \mathrm{m}(\mathrm{z}=\mathrm{Lx} \bullet \mathrm{L} \sim \mathrm{x} \bullet \sim \mathrm{L} \sim \mathrm{x}), \mathrm{t}, \mathrm{e}\right)\right\}-\mathrm{a}_{2 . \mathrm{r}}\left(\mathrm{p}_{2^{\prime}} \mathrm{m}\left(=\mathrm{n}_{2}\right)( \pm \mathrm{z}), \mathrm{t}, \mathrm{e}\right)
$$

en donde el acto $a_{2 . r}$ puede ser múltiple, con $r=1,2,3 \ldots . n$, con lo que se tiene la representación de un proceso de creación normativa, integrado por diversos actos ordenados temporalmente y en una secuencia determinada.

La regla que especifica el procedimiento de emisión de un mandato no necesariamente, aunque puede hacerlo, debe referirse a individuos particulares, concretos, sino que puede, de manera tan complicada como se quiera, determinar las características que han de cumplir los individuos facultados para emitir mandatos complementados semánticamente, ${ }^{18}$ es decir, normas positivas. Por tanto, la regla que establece el proceso de creación de una norma puede ser general o particular. En los sistemas modernos, estas reglas son muchas veces generales.

Con los elementos anteriores, podemos representar el esquema del orden jurídico, de la siguiente forma: ${ }^{19}$

\section{E S Q U E M A}

(e0) $n_{B} F\left(a_{1 . r(p, m(=), t, e)}\right) \quad$ Norma Básica

(e1) $a_{1 . r\left(p, m\left(=n_{1}\right.\right.} F\left[a_{2 . r(p, m(z=L \mathbf{x} \bullet \mathbf{L} \sim \mathbf{x} \bullet \sim \sim \sim \sim x), t, e}\right]_{)), t, e)}$ Proceso Constituyente Constitución derechos fundamentales

(e2) $a_{2 . r(p, m(=)} n_{2} F\left[a_{3 . r(p, m(w), t, e)}\right]_{( \pm \mathbf{z})), t, e)} \quad$ Proceso Legislativo Ley

(e3) $a_{3 . r(p, m(=)} n_{3} F\left[a_{4 . r(p, m(y), t, e)}\right]_{( \pm \mathbf{w} \bullet \mathbf{z})), t, e)} \quad$ Proceso Reglamentario Reglamento

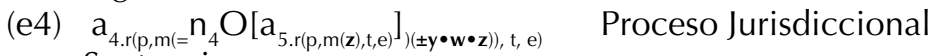
Sentencia

(e5) $a_{5 . r(p, m[z]( \pm y \cdot w \bullet z) t, e)} \quad$ Ejecución sentencia . 
Este es el esquema de un orden jurídico positivo moderno. Debe observarse que conforme al mismo, toda norma jurídica está representada como el significado de un acto de producción de normas, i.e., dentro de la dimensión material de realización del acto $a_{i, r}$. Cada acto de producción normativa es presentado en sus dimensiones de realización personal $p$, material $m$, temporal t y espacial e. Cuando estas dimensiones de realización de los actos creadores de normas, son a su vez el contenido de una norma jurídica, reciben el nombre de "ámbitos de validez" de la norma. Debe enfatizarse especialmente que la norma creada es el sentido o significado del acto de su producción, por lo que se encuentra colocada dentro de la dimensión material de realización del acto de producción normativa. La norma creada por un acto $\mathrm{NO}$ es una consecuencia del mismo.

$\mathrm{n}_{1}$ es la Constitución positiva. Ella debe entenderse como una norma que establece fundamentalmente facultades $\mathbf{n}_{\mathbf{1}} \mathbf{F}\left(\mathbf{a}_{2 . r}(\mathbf{p}, \mathbf{m}(-), \mathbf{t}, \mathbf{e})\right.$, lo que significa que establece los procesos de creación de otras normas $\mathrm{n}_{2^{\prime}}$..etc., a las que podemos denominar "condicionadas" o "inferiores" o "subsecuentes", determinando sus ámbitos de validez. Estos, tal como se presentan en los esquemas, son el contenido de las normas que establecen las dimensiones de realización de las conductas procesales creadoras de otras normas. Lo que en la norma son los ámbitos de validez, en las conductas ejecutoras de las normas, son la ocurrencia, personal, material, temporal y espacial del acto ejecutor de la norma. El esquema presenta, en primer lugar, que la Constitución es una norma positiva, creada por un procedimiento determinado $\mathbf{a}_{1 . r}(\mathbf{p}, \mathbf{m}(), \mathbf{t}, \mathbf{e})$; el contenido de la dimensión material de realización del proceso constituyente son las normas constitucionales; éstas establecen los ámbitos de validez de las normas que establecen los procesos de creación de las normas inferiores $a_{2, r}$ (parte orgánica); el esquema igualmente indica con la constitución $\mathbf{n}_{1^{\prime}}$ (que, como se acaba de decir, es el contenido de la dimensión material de realización del proceso constituyente), una concepción muy especial del orden normativo: el ámbito material de validez de la constitución, i.e., $\mathbf{m}(\mathbf{z}=\mathbf{L} \mathbf{x} \bullet \mathbf{L} \sim \mathbf{x} \bullet \sim \mathbf{L} \sim \mathbf{x})$, debe entenderse como determinando el contenido del acto o de los actos de creación de las normas condicionadas o subsecuentes. Las disposiciones de la constitución que constituyen el ámbito material de validez $\mathrm{m}(\mathrm{z})$ son normas incompletas, evidentemente. Esas determinaciones del contenido son llamadas "garantías individuales" o "derechos públicos subjetivos" o "derechos humanos", terminología por demás imprecisa e ideológica. Deben comprenderse en relación de unidad con las demás determinaciones constitucionales, pues de otra manera se corre el riesgo de no captar la función normativa específica que desempeñan dentro del orden jurídico. Este contenido está simbolizado con $\mathrm{m}(\mathrm{z})$. Este contenido contiene un conjunto de principios que deben respetar o cumplir todas las demás normas dependientes. 
Éstas no reproducen el contenido de la constitución, sino que lo respetan, lo cumplen de la manera explicada más arriba, según se trate de $\mathbf{L x}, \mathbf{L} \sim \mathbf{x} 0 \sim \mathbf{L} \sim \mathbf{x}$, es decir, de los contenidos necesarios, excluidos o potestativos, respectivamente. Por ello, en la ocurrencia del acto creador de la norma $\mathrm{n}_{2}$, es decir, de la norma directamente dependiente de la constitución, la ley, su contenido no es $\mathbf{m}(\mathbf{z})$, $\operatorname{sino} \mathbf{m}(\mathbf{w})$, porque la ley tiene un contenido propio $\mathbf{w}$ que puede concordar o no con el contenido a establecido por la constitución, contenido que es determinante de los contenidos de las normas dependientes o inferiores, i.e., ( $\mathbf{( z )}$ ). Lo mismo acontece con las demás normas y actos de ejecución, que tienen sus propios contenidos, adicionales a los de las normas condicionantes o precedentes, pero cumpliendo con su sentido o teniendo el sentido que esos contenidos determinan. Las normas constitucionales a las que nos referimos están formuladas con términos muy generales, a veces, generalísimos. Por la textura abierta del lenguaje natural, admiten una pluralidad muy abundante de interpretaciones. No es el tema de este ensayo, pero la problemática desarrollada en las últimas décadas sobre la dualidad de normas (o reglas) y principios puede encontrar en el modus operandi de estas normas el fundamento de su explicitación, siempre y cuando no se incurra en la admisión de normas no positivas (iusnaturalistas).

Todo ello desemboca en una norma que ya no establece facultades con ciertos contenidos, sino directamente la obligación de llevar a cabo una cierta conducta o una norma que nulifica otra norma de manera condicionada. La conducta de cumplimiento de la obligación tiene la ocurrencia de los ámbitos de validez de la norma y su significado es el producto, para decirlo de esta manera, de todos los condicionamientos de las normas condicionantes. Es como si los ámbitos materiales de validez de las normas condicionantes se conjuntaran en el establecimiento de la conducta obligatoria. Nada de extraño tiene esto.

\section{La nulidad y la derogación 20}

A continuación, con el objeto de completar la exposición, quisiera presentar los esquemas de las normas que establecen la derogación y la anulación de una norma. De manera convencional podemos distinguir conceptualmente a la derogación de la anulación de una norma.

Tanto la derogación como la anulación (nulidad) son el contenido de una facultad, consistente en la fijación de la fecha final ff del ámbito temporal de validez (vigencia) de una norma, hecha por un órgano jurídico. No hay actos de derogación o de anulación implícitos. Toda función jurídica debe concebirse como una función positiva, es decir, puesta o establecida por un acto orgánico. 
Convencionalmente podemos distinguirlas diciendo que la derogación es la fijación incondicionada de la fecha final de vigencia de una norma, generalmente hecha por el mismo órgano que la estableció; en cambio, la anulación es la fijación de la fecha final de vigencia de una norma hecha condicionalmente y generalmente por un órgano distinto del que la creó. En lo que sigue, utilizaremos la expresión "anulación" para referirnos indistintamente a la anulación y a la derogación.

La facultad para anular una norma tiene la siguiente estructura general:

$$
n_{j} F_{n u l}\left(a_{i}(p, m, t, e)\right)
$$

El contenido del acto que establece la nulidad de una norma, i.e., en nuestro esquema $m$, está por la fijación condicionada de la fecha final de vigencia (ff) de una norma. En lo que sigue haremos más explícito este esquema.

Como la norma que se anula o nulifica tiene ámbitos de validez,

$$
n_{k}(p, m, t, e)
$$

cuando se fija la fecha final de validez $\mathrm{ff}$ de la norma tiene que determinarse el status de cada uno de sus otros ámbitos. Con ello, la norma que establece la facultad de anulación condicionada de otra norma tiene la siguiente estructura:

$$
n_{j} F_{n u l}=n_{j}\left(a_{i}\left(p, m\left(n_{k\left(p, m, t\left(-, c^{*} \rightarrow r f f, e\right)\right.}\right), t, e\right)\right)
$$

lo que significa que existe una norma $n_{j}$ que establece la facultad de nulificar la norma $n_{k}(p, m, t, e)$, lo que significa que determina de manera condicionada la fecha final ff del ámbito temporal de validez de la norma. Corolario de lo anterior es que la derogación y la anulación no pueden ser concebidas como sanciones, por varias razones, que no es el caso exponer en este lugar, de las cuales la fundamental es que la facultad no se reduce (y no puede explicarse) con los conceptos de la estática jurídica, en el sentido de KELSEN.

\section{i. Derogación.}

Debemos distinguir dos casos generales que se pueden presentar en el momento de emisión de cualquier norma $n_{j}$ : 
1. El órgano que emite la norma $\mathrm{n}_{\mathrm{j}+1}$ fija su fecha inicial de validez fi del ámbito temporal $\mathbf{t}$ y lo mismo su fecha final de vigencia ff, en el mismo acto o en actos diferentes. Entonces

$$
n_{j}\left(a_{i+1(p, m, t, e)}\right)-a_{i+1}\left(p, m\left(=n_{j+1(p, m, t(f, f f), e)}\right), t, e\right)
$$

Estos son los casos de la emisión transitoria de normas, emitidas para atender una situación urgente o temporalmente limitada, como un estado de emergencia.

Pero lo más común es que el órgano creador de la norma $\mathrm{n}_{\mathrm{j}+1}$ solamente fije la fecha inicial de la vigencia fi, dejando indeterminada la fecha final de la vigencia ff:

$$
n_{j}\left(a_{i+1(p, m, t, e)}\right)-a_{i+1}\left(p, m\left(=n_{j+1(p, m, t(f i,-), e)}\right), t, e\right)
$$

La derogación consiste en la realización de un acto $\mathrm{a}_{\mathrm{i}+1}$ del mismo órgano que creó la norma, siguiendo el mismo proceso de creación, cuyo contenido es la fijación o establecimiento de la ff de t de esa norma.

$$
n_{j}\left(a_{i+1(p, m, t, e)}\right)-a_{i+1}\left(p, m\left(=n_{j+1(p, m, t(t, f f), e)}\right), t, e\right)
$$

ii. Nulificación.

La segunda posibilidad que se presenta es cuando otro órgano está facultado para nulificar condicionadamente una norma. Por tanto, tiene que existir una norma que faculte la fijación de la ff de t de la otra norma.

$$
n_{j} F_{n u l}=n_{j}\left(a_{i+1}\left(p, m\left(=n_{k\left(p, m, t\left(-, c^{*}->f f\right), e\right.}\right), t, e\right)\right)
$$

¿Qué dice esta fórmula? La norma $\mathrm{n}_{\mathrm{j}}$ que establece la facultad para anular otra norma, como acontece con los tribunales constitucionales, establece el proceso de creación $a_{i+1}$ de la norma anulatoria, cuyo sentido es la fijación condicionada de la fecha final de vigencia de la norma anulada $\mathrm{n}_{\mathrm{k},}$ o sea, c* (7)ff.

En el caso, el ámbito material de validez de la norma anulatoria, su contenido, está referido a la norma respecto de la cual va a establecer la fecha final ff del ámbito temporal de $\mathrm{n}_{\mathrm{k}^{\prime}}$ si se dan ciertas condiciones, como por ejemplo, que se establezca su contradicción con otra norma, es decir, alguna irregularidad. El establecimiento de la fecha final ff de t condicionado a la realización de ciertos 
supuestos o condiciones, está representado por $\mathrm{t}\left(-, \mathrm{C}^{*}\right.$ (7) ff), en el que aparece un condicional, cuyo antecedente es c* y cuyo consecuente es ff. Todos los posibles casos de irregularidad que se han estudiado más arriba encuentran aquí su lugar sistemático. Es necesario destacar que en la casi totalidad de casos de anulación condicionada, el antecedente del condicional consiste en la determinación de una posible contradicción o irregularidad entre la norma anulada y otra u otras que se toman como marco de referencia para determinar la irregularidad. Las normas condicionantes (superiores) son las que proporcionan los criterios de irregularidad, como hemos visto. Ellas llevan a cabo dos funciones:

1. Establecen el procedimiento de creación de las otras normas y

2. Sirven de criterio de anulación de una norma por su irregularidad.

Como la norma que se anula tiene sus ámbitos de validez, la fijación de la ff de su ámbito temporal tiene que determinar el status de cada uno de esos ámbitos, como resultado de la fijación de esa fecha final de la vigencia. Lo que quiero decir es que la norma anulatoria, al establecer la fecha final de su vigencia $\mathrm{ff}$, puede hacerlo con referencia a la totalidad de los elementos de la norma o sólo a alguno de ellos. La regla general y más simple es la fijación lisa y llana de la ff, comprendiendo a todos los ámbitos de validez de la norma derogada.

\section{La omisión fundamental en el ensayo que se comenta}

Con base en lo anterior, debemos hacer la siguiente observación adicional y que tiene carácter fundamental: los autores del ensayo omiten relacionar de manera sistemática la inconstitucionalidad con la anulabilidad de la norma. Nuevamente creo que el origen de esta omisión radica en que consideran la inconstitucionalidad como "dada", que es a priori, que no es el objeto de un acto jurídico por parte de otro órgano estatal, o lo que es lo mismo, que no tiene carácter constitutivo. Si se prescinde de este supuesto, que ha mostrado su perniciosidad a lo largo de este ensayo, las cosas resultan más fáciles de resolver y no se cae en contradicciones insolubles.

Desde el punto de vista expresado, la ley emitida es una norma existente. No se sabe ni se ha determinado si es o no constitucional. La determinación de ello quedará a cargo de los sujetos que más adelante examinaremos. Objetivamente hablando, la inconstitucionalidad se encuentra ligada de manera esencial con la anulabilidad de la norma inconstitucional. Si no hay anulabilidad, no hay inconstitucionalidad. Y, por lo mostrado más arriba, la anulabilidad es la determinación positiva condicional (por la decisión de la existencia de una 
incompatibilidad, formal o material, con la constitución ( $c^{*}$ (7) ff) de la fecha final ff de la validez de la norma, i.e., $\left(a_{i+1}\left(p, m\left(=n_{k\left(p, m, t\left(-, c^{*} \rightarrow-f f\right), e\right.}\right), t, e\right)\right)$. Esto simplemente no está explicitado en el trabajo que se comenta. En él se habla de la derogación, la que ciertamente es una modalidad de la terminación de la validez de una norma, pero que no expresa, el sentido de la inconstitucionalidad. La derogación puede ser lisa y llana, tener carácter incondicional: el legislador puede derogar una ley, por cualquier motivo que desee, por Ej., inconveniencia política o económica o social, etc. En cambio, la anulabilidad siempre es condicionada y, generalmente, por la irregularidad en su creación o en su contenido, en relación con cualquier norma que la determine, constitucional o de otra índole. Quisiera transcribir un breve párrafo de KELSEN que expresa con suma claridad la significación del control de la constitucionalidad:

Una Constitución que carezca de la garantía de la anulabilidad de los actos inconstitucionales no es una Constitución plenamente obligatoria, en sentido técnico. Aunque en general no se tenga conciencia de ello (porque una teoría dominada por la política no permite esta toma de conciencia( una Constitución en la cual los actos inconstitucionales y, en particular, las leyes inconstitucionales sigan conservando su validez al no ser posible anularlos por su inconstitucionalidad( equivale, desde el punto de vista propiamente jurídico, a poco más que unos buenos deseos desprovistos de fuerza obligatoria. ${ }^{21}$

\section{Sujetos facultados para determinar la regularidad de una norma}

Hasta la fecha no he encontrado autor alguno que haya intentado exponer las tesis de KELSEN sobre los sujetos facultados para establecer la regularidad de las normas y las diversas modalidades que puede adoptar el orden jurídico al respecto. La solución de este problema expresa, en esencia, el contenido de la Norma Fundante Básica de Kelsen o la Regla de Reconocimiento de Hart. Creo que ambas formulaciones son idénticas en cuanto a su contenido esencial, por más que se las ha intentado presentar como soluciones dispares. Esta identidad aparece con claridad si se entiende que la Norma Fundante Básica es el criterio sustantivo para determinar la regularidad de una norma, KeLSEN diría, para su validez y pertenencia a un orden jurídico; con ello, se ha omitido determinar cuáles son los sujetos facultados para aplicar ese criterio sustantivo de regularidad. Por su parte, HART no expresa el criterio sustantivo y sólo determina de manera vaga los sujetos que hacen el "reconocimiento" de la norma como norma jurídica. KeLSEN expresa, en primer término, el criterio sustantivo (omitido por HART) y, posteriormente, en un capítulo nunca analizado de su TGE, a los sujetos facultados 
para determinar la regularidad de la norma y su pertenencia a un orden jurídico determinado.

La tesis de KELSEN es muy general en su planteamiento: no se refiere a ningún órgano en especial, sino a todos en general. Una posible forma adecuada de exponer estas tesis es la de presentar un problema que aparece tratado en la TGDE, no especialmente dedicado al problema presente:

Como la función de los tribunales en su capacidad de órganos jurisdiccionales consiste en aplicar, a casos concretos, las normas generales del derecho legislado o consuetudinario, el tribunal tiene que decidir qué norma general es aplicable a cada uno de esos casos. Los tribunales están obligados a investigar si el orden jurídico contiene una norma que enlace una sanción al comportamiento que el Ministerio Público considera como delito, o a la conducta que el particular demandante reputa violatoria de la ley civil, así como la sanción establecida al efecto. El tribunal no sólo tiene que resolver la quaestio facti sino también la quaestio juris. Ha de examinar, asimismo, si la norma general que pretende aplicar es realmente válida, es decir, si ha sido creada en la forma prescrita por la Constitución... El tribunal tiene que declarar la existencia de tal norma del mismo modo que está obligado a establecer la existencia del acto violatorio. ${ }^{22}$

Pero no sólo los tribunales: todos los órganos jurídicos se encuentran en la necesidad de decidir si la norma que prima facie les exige ejecución, es una norma perteneciente al orden jurídico. Para ello, colocándose en el punto de vista interno o inmanente al derecho, tiene que determinar si la norma respectiva es una norma existente y regular, si ha sido creada con arreglo a los procedimientos y con los contenidos establecidos por las normas condicionantes (superiores). Esto convierte al contenido de toda norma condicionada (inferior) en una norma derrotable, en el siguiente sentido: si se expresa el contenido de la norma que exige obediencia al órgano correspondiente como un condicional que relaciona un supuesto de hecho con una consecuencia modalizada deónticamente, i.e., $\mathrm{p}$ (7) $X^{*} q$, donde $p$ es el supuesto de hecho y $X^{*}$ está por cualquiera de los operadores modales $\mathrm{P}$ (permisión), Ph (prohibición), O (obligación), F (facultad), entonces el contenido normativo de una ley tiene que expresarse con un condicional que elimine la derrotabilidad del condicional, expresando la expansión del antecedente. Lo que quiero decir es lo siguiente, utilizando los símbolos usados anteriormente en el esquema:

Aquí debemos hacer una distinción muy importante: me refiero a las normas derrotables de manera formal o adjetiva (derrotabilidad adjetiva) y normas derrotables de manera material o sustantiva (derrotabilidad sustantiva). Expondremos a continuación el concepto de la derrotabilidad adjetiva. ${ }^{23}$ 
En nuestro esquema, en (e2) podemos distinguir dos partes esenciales o fundamentales: el conjunto de actos procedimentales creadores de la norma subsecuente

$\mathrm{a}_{2 \cdot \mathrm{r}(\mathrm{p}, \mathrm{m}(-), \mathrm{t}, \mathrm{e})}$

y la norma creada por el proceso respectivo, especificada dentro de la dimensión material de realización de los actos del procedimiento

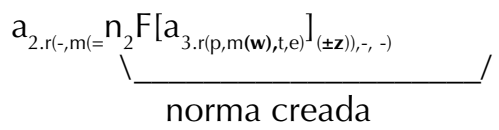

Analicemos, en primer término, la derrotabilidad formal o adjetiva. Supondremos que se quiere expresar el contenido conjunto de la ley $\mathrm{w}$ por medio de enunciados condicionales $p$ (7) $X^{*} q$ (donde $X^{*}=\mathbf{O}, \mathbf{P}, \mathbf{P h}, \mathbf{F}$ ). Si simbolizamos el condicional derrotable como $p>X^{*} q$, entonces el contenido conjunto de la ley, debe propiamente ser representado de la siguiente manera: $p \bullet a_{2 . r}(7) X^{*} q$. Si acontece que p . $\left(\sim a_{2 . r}\right)\left(7 \sim\left(X^{*} q\right)\right.$ decimos que el condicional ha sido derrotado por una violación de carácter procesal o adjetivo.

En relación con la derrotabilidad sustancial o material debe seguirse un procedimiento similar: en el esquema representamos el contenido conjunto de la constitución en su aspecto sustantivo con la letra z. Por lo tanto, podemos afirmar que tanto $\sim z$, como $\sim a_{i, r^{\prime}}$ son irregularidades, por lo que cualquier condicional normativo que lo contenga es derrotable, en tanto admite la anulabilidad de esos condicionales para el caso de que exista alguna irregularidad en la ley en relación con el contenido de la constitución. En este caso, estamos en presencia de una inconstitucionalidad material. Por tanto, $\mathrm{p} \bullet(\sim \mathrm{z})(7) \sim\left(\mathrm{X}^{*} \mathrm{q}\right)$, i.e., el condicional normativo es derrotable y esto quiere decir que es anulable, como veremos más adelante. Aceptemos provisionalmente que el esquema inmediatamente anterior expresa la derrotabilidad del condicional normativo. Si queremos presentar de manera conjunta los elementos implícitos que pueden derrotar, tanto adjetiva como substantivamente, los condicionales normativos, tendremos lo siguiente (los elementos entre paréntesis derrotan al condicional normativo):

$$
\mathrm{p} \bullet\left(\sim \mathrm{z} \vee \sim \mathrm{a}_{2 . \mathrm{r}}\right)(7) \sim\left(\mathrm{X}^{*} \mathrm{q}\right) \text {, con } \mathrm{r}=1,2,3 \ldots \mathrm{n} \text {. }
$$

Ya hemos explicado que $\sim a_{2 . r,}$ son los elementos que derrotan formal o adjetivamente al enunciado condicional. z está por los elementos que derrotan 
material o substantivamente al condicional normativo.

La Constitución tiene un segundo elemento que hemos representado de la siguiente manera: $\mathrm{z}=\mathrm{Lx} \bullet \mathrm{L} \sim \mathrm{x} \bullet \sim \mathrm{L} \sim \mathrm{X}$. Estos son los contenidos que constituyen la llamada "parte dogmática" de la Constitución. Ella contiene las determinaciones necesarias, excluidas o potestativas de las normas condicionadas creadas siguiendo el proceso legislativo señalado en el primer elemento. Por lo tanto, estas prescripciones constitucionales sobre el contenido de las leyes, i.e., el de las normas generales dictadas siguiente el proceso legislativo $\left[a_{2 . r}(p, m, t, e)\right]$, deben figurar también como elementos que pueden derrotar a la ley, pues su función no es otra que determinar el contenido de las leyes dictadas, en cuanto limitan el contenido de las mismas de las tres maneras indicadas, es decir, de manera necesaria ( $L x)$, de manera excluida $(L \sim x)$ y de manera potestativa $(\sim L \sim x)$, en donde claramente el símbolo " $\mathrm{L}$ " es el operador modal de la necesidad. Por ello, siguiendo el mismo método que hemos presentado con anterioridad, debemos indicar en nuestro esquema general de un condicional derrotable (29) que describe una norma legal, los elementos materiales que lo derrotarán:

$$
\mathrm{p} \bullet\left\{[\sim(\mathbf{L x} \Uparrow \mathbf{L} \sim \mathrm{x} \Uparrow \sim \mathbf{L} \sim \mathrm{x})] \vee\left[\sim \mathrm{a}_{2.1} \vee \sim \mathrm{a}_{2.2 \ldots} \ldots \sim \mathrm{a}_{2.7}\right]\right\}(?)(7) \sim\left(\mathrm{X}^{*} \mathrm{q}_{\mathbf{j}}\right)
$$

Expresado lo anterior en palabras, este esquema representa que el enunciado que describe una norma cualquiera que bajo cierta condición establece como obligatoria (permitida, prohibida o facultada) una cierta conducta $p$ (7) $\mathrm{X}^{*} \mathrm{q}_{\mathrm{j}^{\prime}}$ es derrotable cuando se pueda llegar a comprobar que existió alguna irregularidad en el proceso de su creación (irregularidad adjetiva o procesal) $\left(\sim \mathrm{a}_{2.1} \vee \sim \mathrm{a}_{2.2 \ldots} \sim \mathrm{a}_{2.7}\right)$ o tiene un contenido que se encuentra en contradicción con las determinaciones constitucionales que lo determinan de manera necesaria, excluida o potestativa (irregularidad material o sustantiva) $\sim \mathrm{Z}(=\sim(\mathbf{L x} \Uparrow \mathbf{L} \sim \mathrm{x} \Uparrow \sim \mathbf{L} \sim \mathrm{x}))$

En el esquema (30) aparece la expresión $\sim\left(X^{*} q_{i}\right)$, que expresa la derrotabilidad. Ahora debemos hacerla explícita.

Pongamos como ejemplo el caso de una ley que establece una prohibición determinada o una obligación u otorga una facultad. La norma correspondiente es:

$p$ (7) $X^{*} q(-,-,(f i,-),-)$

Entonces, 


$$
\text { p } 7 X^{*} q\left(-,-,\left(f i, c^{*}(7 f f),-\right)\right)
$$

en donde ya se ha establecido la fecha final del ámbito temporal de validez de la norma legal y, por lo tanto, ha sido anulada. Con ello, hemos establecido la siguiente igualdad:

$$
\sim\left(X^{*} \mathrm{q}\right)=\mathrm{X}^{*} \mathrm{q}\left(-,-,\left(\mathrm{fi}, \mathrm{c}^{*}(\mathrm{D} \mathrm{ff}),-\right)\right)
$$

Expresado en palabras, (35) expresa que la derrotabilidad de la norma $\sim\left(X^{*} q\right)$ significa que se haya establecido la fecha final ff del ámbito temporal de validez de la norma, lo cual es otra forma de expresar que la conducta modalizada por $\mathrm{X}^{*}$ ya no ha de realizarse con la característica deóntica que le corresponda dependiendo de $\mathrm{X}^{*}$ esté por $\mathrm{P}, \mathrm{Ph}, \mathrm{O}$ o F.

Por lo tanto, sólo nos queda por hacer explícita la c*, i.e., la condición para establecer la fecha final de la validez de la norma en cuestión. Ya quedó expresado con anterioridad:

$$
p \text { (7) } X^{*}\left(-,-,\left(f i,\left(\sim z \vee \sim a_{2 . r}\right)(7 f f),-\right)\right)
$$

lo que significa que se establece la fecha final de la validez de la norma bajo la condición de su irregularidad material o formal.

El problema que ahora se presenta es el siguiente: determinar los sujetos que pueden establecer la anulación de la norma irregular. Este interrogante lo puede presentarse de la forma siguiente:

$$
p \oslash X^{*} q\left(?,-,\left(f i, c^{*}(7 f f),-\right)\right)
$$

donde el lugar o posición correspondiente al ámbito personal de validez del condicional derrotable aparece con el signo "?", para indicar que nos cuestionamos sobre él.

KELSEN da la siguiente respuesta:

Si se investiga sin prejuicios y según principios puramente positivistas la situación jurídica que resulta, en el caso de silencio del legislador, para el sujeto que tiene frente a sí una pirámide de normas: constitución, ley, reglamento, disposición individual, cada una de las cuales le exige obediencia, el sentido de todas ellas no puede ser otro que el siguiente: "obedece a una disposición individual, pero no a una disposición arbitraria; acata solamente aquella que ha sido dictada conforme 
a la norma general de la ley, pues sólo tal disposición es una norma obligatoria, y sólo a ella pretende la ley que le prestes obediencia; y qué sea una ley, qué hecho has de respetar como tal ley, eso no puede determinarse sino con arreglo a la constitución". (Cursiva y negrita agregada por USO) El Derecho positivo puede limitar este examen y puede orientarlo en determinadas direcciones. Si falta esta limitación (acerca de cuya necesidad o conveniencia política nada hemos de decir( la teoría no puede llegar a otro resultado que éste: aquel que ha de ejecutar la norma, ha de examinar y decidir también si es o no una norma regular y, por tanto, ejecutable. ${ }^{24}$

Como puede observarse de este texto, la facultad para anular una norma irregular, es una decisión positiva del órgano ejecutor, entendido en sentido lato, para el caso de que exista silencio del legislador. Estamos frente al caso en que nada diga el orden jurídico al respecto. El sentido todo del orden jurídico es el expresado por las palabras de KELSEN, principio al que podemos denominar "Norma Fundante Básica" o "Regla de Reconocimiento", pues su contenido no es otro que el de especificar cuáles son los criterios para reconocer o determinar, por parte de los órganos ejecutores, las normas jurídicas que son válidas. Por lo tanto, para el caso de silencio del legislador, el órgano ejecutor está facultado para establecer la fecha final ff del ámbito de validez de las normas:

$$
\text { p (7) X*q(órgano ejecutor, -, (fi, c* (7ff), -)) }
$$

Conforme a nuestro principio de la positividad, toda norma jurídica está asociada a un acto de establecimiento, a un acto de producción. Si hay silencio del legislador, no está positivamente establecido que la inejecución de la norma sea un acto ilícito, por la sencilla razón de que no se encuentra establecida la sanción correspondiente. Si no existe la sanción establecida para el caso de inejecución de la norma, el órgano puede inejecutar y no se suscita ninguna consecuencia sancionatoria. La inejecución no es, entonces, un acto ilícito. ${ }^{25}$ Además, conforme el principio de que lo que no está prohibido está permitido, puede decirse que la inejecución está permitida por el orden jurídico, siempre y cuando juzguemos la inejecución, no desde la perspectiva del concepto de la facultad, tal como se ha definido más arriba, sino con los conceptos derivados de la concepción del derecho como un orden coactivo, i.e., con los conceptos P, $\mathrm{Ph}$ y $\mathrm{O}$. Por lo anterior, es claramente observable que el supuesto de las afirmaciones anteriores consiste en la unión de los conceptos derivados del fundamental de la facultad con los conceptos propios de la Estática jurídica. Es en este lugar donde ambos tipos de conceptos se unen, se sintetizan en una unidad superior, para producir el sentido completo del orden jurídico, la forma como opera el derecho positivo. 
Podría pensarse en un principio diferente y exactamente contrario al expresado. Suponer que toda inejecución de una norma es un acto ilícito y que, por tanto, toda inejecución está sancionada. Entonces, el contenido de las normas jurídicas cambiaría por completo. Las normas jurídicas tendrían que establecer los casos en que estarían autorizados los órganos jurídicos para inejecutar, sin que se les aplicara una sanción. Estaríamos en el caso que me gustaría comparar con el profundo drama de Heinrich von Kleist "El Príncipe de Homburgo", en el que el príncipe, desobedeciendo la orden de sólo atacar cuando se le ordenara, gana una batalla, por su oportuna intervención, la que lleva a cabo sin la orden correspondiente; el príncipe es recompensado con honores por el acto heroico, pero sancionado a continuación con la pena de muerte por haber desobedecido una orden en una situación de guerra. Es claro que el príncipe no estaba jurídicamente facultado para examinar y decidir la regularidad de la orden de no atacar. Este principio alterno $\mathrm{NO}$ es aceptable, por el principio de positividad expuesto más arriba. Si no está establecido positivamente la sanción por la inejecución de una norma, dicha inejecución no es un acto ilícito. Las sanciones no existen de manera natural, sino que son el contenido específico de las normas jurídicas. No hay sanciones naturales, sino sólo sanciones positivamente establecidas. Por ello, el principio que se comenta y que se encuentra en la base de muchas doctrinas administrativas, no tiene un fundamento científico. ${ }^{26}$

Ahora debe relacionarse estos fenómenos con las consecuencias jurídicas que se derivan para el caso de inejecución de la norma que exige obediencia, según su sentido subjetivo.

(...) la cuestión de la competencia examinadora (de la regularidad de la norma: USO) no es más que la cuestión acerca del deber de obediencia del órgano ejecutivo, por lo cual la cuestión tiene que plantearse en este sentido (desde el punto de vista técnico(: ¿cuáles son las consecuencias jurídicas del hecho de que un órgano (en sentido amplio) no ejecute o incumpla la norma encomendada a su ejecución, por estimarla irregular? Si este hecho no se sanciona, no es un hecho ilícito; es decir, el órgano ejecutivo puede no cumplir o dejar de ejecutar la norma encomendada a su ejecución, si la estima irregular, sin que tenga que temer ninguna sanción; no está, pues, obligado, pero sí autorizado a examinar y decidir por sí mismo la regularidad de las normas. ${ }^{27}$

Queda claro que esta norma que pretende obediencia, cuya validez se examina, es una incógnita, que ha de despejar el órgano ejecutor. Si la inejecución no trae consecuencia jurídica alguna, el órgano ejecutor está facultado para examinar y decidir su irregularidad y, por tanto, su anulabilidad. 
Si el que ha de ejecutar la norma debe decidir su regularidad, no se le puede castigar, no se le puede hacer responsable por la inejecución de la misma. ${ }^{28}$

Sería más correcto afirmar que si el órgano no está sancionado por la inejecución, entonces opera en toda su plenitud el principio central y debe decirse que se encuentra facultado para examinar y decidir sobre la regularidad de la norma que pretende ejecución.

Veamos el caso siguiente:

Si el orden jurídico determina que el órgano ejecutor puede ser hecho responsable por otro en virtud del incumplimiento de la norma, determínase, eo ipso, que no es el ejecutor, sino otro, quien ha de decidir si la norma es regular y si, por consiguiente, su incumplimiento es o no desobediencia punible, un hecho antijurídico. ${ }^{29}$

Si este es el caso, debe considerarse que la norma que, según su sentido subjetivo, debe ejecutarse, es válida y obligatoria para el ejecutor, el cual no puede inejecutarla válidamente por irregularidad, pues hacerlo implica que otro órgano lo sancione por la antijuridicidad cometida.

Esta facultad fundamental de examinar y decidir sobre la regularidad de la norma a ejecutarse, puede modalizarse y restringirse en diversos sentidos, que no es el caso exponer en este lugar. Todas estas restricciones a este principio fundamental tipifican los diversos métodos de control de la regularidad por el órgano ejecutor o por otros órganos diversos, competentes para juzgar y en su caso sancionar la inejecución por parte del órgano a quien se le ha encomendado la ejecución de ciertas y determinadas normas. En el ensayo que se comenta se presentan diversos sistemas de control de la constitucionalidad, que podrían ser analizados desde la perspectiva aportada por los conceptos anteriores.

Se han presentado históricamente diversos sistemas de control de la regularidad. Si un órgano inejecuta la norma encomendada a su ejecución, puede ser i) sancionado o ii) no sancionado. Ya vimos el caso en que no se establece sanción alguna en todos los casos de inejecución: el órgano entonces se encuentra facultado para examinar y decidir sobre la regularidad de la norma. Puede acontecer que el órgano inejecute; el órgano superior competente para decidir si la inejecución es ilícita o no, decide que la norma es irregular, i.e., coincide con el criterio del órgano ejecutor de que la norma es inejecutable por irregular. Entonces, no se suscita ninguna sanción. La primera inejecución la realizó el órgano por su cuenta y riesgo. Puede acontecer que se establezca que la primera inejecución del órgano 
no se sancione y sólo se establezca la sanción para el caso de que el órgano revisor no confirme la decisión en primera instancia y el órgano de primera instancia inejecute la decisión del órgano revisor de segunda instancia.

Las modalidades de la decisión de regularidad son variadas para el caso de que lo que se decide que es irregular sea un acto concreto o una norma de carácter general. Todas las modalidades son posibles. El establecimiento de la inconstitucionalidad de una ley puede tener efectos generales o sólo efectos para el caso particular del sujeto que ha solicitado el control de la constitucionalidad. A su vez, si los efectos son generales, como la sentencia que establece la inconstitucionalidad es una norma, tiene ámbitos de validez que pueden adoptar cualquier modalidad. Por ejemplo, puede modalizarse el ámbito temporal, de manera que la terminación de la validez temporal de la norma surta efectos a partir de una determinada fecha o, en el ámbito espacial, se anule sólo en ciertas partes del territorio o sobre cierta clase de personas, etc.

Además de lo anterior, podrían hacerse observaciones sobre las múltiples tesis, interesantes todas ellas, contenidas en el ensayo que se analiza. Otros comentaristas analizarán otros temas, por lo que en este punto, doy por terminadas mis observaciones. 


\section{Notas}

${ }^{1}$ KeLSEN. TPD2:277.

${ }^{2}$ Cf. Comanducci KCAT.

${ }^{3}$ KeLSEN. TPD1:122-123.

${ }^{4}$ Cf.HART. KDUL, para un análisis y esbozo de una crítica a la tesis que afirma la necesaria unidad del orden jurídico.

${ }^{5}$ Kelsen. TPD1:124-125.

${ }^{6}$ Cf. MétAll. HK. pp. 22-23.

${ }^{7}$ Recuérdese que las obras centrales de su sistema filosófico tienen los siguientes títulos: Lógica del Conocimiento Puro, Ética de la Voluntad Pura y Estética del Sentimiento Puro.

${ }^{3}$ Der Ausdruck "gegeben" ist in der mathematischen Sprache entstanden, vermuthlich in der analytischen Methode P I a $t$ o $n$ s. Die Bedingungen für die Construction der Aufgabe heissen gegeben. E u kli d hat ein besonderes Buch unter dem Titel der D a $t$ a () geschrieben. Was er darunter versteht, zeigt sich in der 4. Definition: "Punkte, Linien und Räume heissen der Lage nach

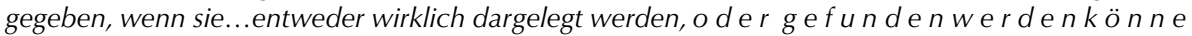
$n$ ". Also wenn sie gefunden werden können heissen sich auch gegeben. Gefunden können sie nur vom Denken werden; darum heissen sie gegeben. Die $D$ a $t$ a der Analysis heissen gegeben...Dem Denken darf nur dasjenige als gegeben gelten, was es selbst aufzufinden vermag. Cohen. LRE:67-68. ${ }^{9}$ Kelsen. TGE. p. 137.

${ }^{10}$ Kelsen. QAJ:67-68.

11 Kelsen. QAJ: 68-69.

${ }^{12}$ Esto tiene semejanza epistemológica con la concepción de la verdad como correspondencia y la concepción de la verdad como construcción, como en la lógica intuicionista.

13 Kelsen.QAJ:71.

14 Parte de lo que se pone a continuación se encuentra expuesto en una ensayo que pronto será publicado en la revista Analisi e Diritto, a cargo de P. Comanducci y R. Guastini, con el título Orden Jurídico y Derrotabilidad Normativa.

${ }^{15}$ Estamos usando este signo de la manera como lo usan Carlos AlChOurrón y Eugenio Bulygin: "Los signos "ト " y "!" serán usados para indicar el tipo de acto lingüístico (aserción u orden) Ilevado a cabo por un hablante no especificado. Estos signos son meros indicadores de lo que el hablante hace cuando emite ciertas palabras, pero ellos no contribuyen al significado (esto es, al contenido conceptual de las palabras usadas). Ellos muestran qué es lo que está haciendo el hablante, pero al hacerlo él no dice qué está haciendo; de esta manera esos indicadores no forman parte de lo que el hablante dice o lo que sus palabras significan, del mismo modo como en el lenguaje ordinario (escrito) el punto o los signos de interrogación o de exclamación no forman parte del significado de la oración, sino que indican qué se está haciendo con ella." (AlChOurrón y BulyGin CEN. pp. 123-124)

${ }^{16}$ Cf. Kelsen TPD2. Cap. VIII y Bayón DIPJ. pp. 97-101.

${ }^{17}$ He empleado el símbolo "L" debido a que, en otro trabajo, desarrollaré una semántica, basado en los conjuntos modelo de HINTIKKA, tal como han sido aplicados por SNYDER. Cf. SNYDER ML.

${ }^{18}$ Los subíndices de $\mathrm{p}, \mathrm{n}$, etc., se explican analizando el Esquema infra.

${ }^{19}$ Cf. SCHMILl. DON.

${ }^{20}$ Cf. Kelsen TGE, TGDE y D; Schmill DAAT y RPTD; Aguiló SD; Alexy TDF y Alchourrón y Bulygin CEN.

${ }^{21}$ Kelsen. GJC:150.

22 Kelsen. TGDE: 148.

${ }^{23}$ Cf. Schmill OJDN, de próxima aparición en Analisi e Diritto; Navarro SNDC; Navarro y DSNJ y y SUCAR TD.

${ }^{24}$ KelSEN. TGE:375. 
${ }^{25}$ Debe observarse que esta afirmación confirma la tesis sustentada anteriormente sobre la independencia de los conceptos de la Estática y los conceptos que se sustentan en el concepto de la facultad. Estas afirmaciones se encuentran bajo el supuesto que el derecho positivo nada dispone sobre las consecuencias jurídicas de la inejecución, consecuencias consistentes en el establecimiento de una sanción bajo el supuesto o condición de la inejecución.

${ }^{26}$ Cf. el capítulo de la "Autolegitimación del Acto de Autoridad" en TGE:381.

27 KELSEN. TGE: 375

${ }^{28}$ KeLSEN. TGE:376.

${ }^{29}$ KeLSEN. TGE:376Notas

\section{Bibliografía}

Agulló, Josep. SD Sobre la Derogación. Ensayo de Dinámica Jurídica. Distribuciones Fontamara, S.A. 1995.

Alchourrón, Carlos y Bulygin, Eugenio. CEN La Concepción Expresiva de las Normas en "Análisis Lógico y Derecho". Centro de Estudios Constitucionales. Madrid. 1991.

Alchourrón, Carlos y Bulygin, Eugenio. NJ. "Norma giuridica" en Analisi e Diritto 1996 a cura P. Comanducci y R. GUASTINI.

Alchourrón, Carlos. DL "Sobre Derecho y Lógica" en Isonomía. Revista de Teoría y Filosofía del Derecho, 13, Octubre 2000.

Alexy, Robert. TDF Teoría de los Derechos Fundamentales. Centro de Estudios Constitucionales. Madrid. 1993. Trad. Ernesto GARZÓN VALDÉs.

Bayón, Juan Carlos. DIPJ "Derrotabilidad, Indeterminación del Derecho y Positivismo Jurídico" en Isonomía. Revista de Teoría y Filosofía del Derecho, 13, Octubre 2000.

COHEN, Hermann. LRE Logik der Reinen Erkenntniss. Bruno Cassirer. Berlin. 1902.

Comanducci, Paolo. KCAT "Kelsen e la Clausola Alternativa Tacita" en Assaggi di Metaetica Due. G. Giappichelli Editore. 1998.

Guastinı, Riccardo. TDDF Teoria e Dogmatica delle Fonti. A. Giuffré Editore. 1998.

HART, H.L.A. CD El Concepto del Derecho. Segunda Edición. Abeledo-Perrot. Buenos aires. 1968. Trad. Genaro R. CARRIÓ.

HarT, H.L.A. KDUL KelSEN's Doctrine of the Unity of Law en "Ethics and Social Justice", edited by Howard E. Kiefer and Milton K. Munitz. State University of New York Press, Albany. 1970

Kelsen, Hans. TGE Teoría General del Estado. Editorial Labor, S.A. 1934. Trad. Luis Legaz Lacambra.

KeLSEN, Hans. TPD1 La Teoría Pura del Derecho. Introducción a la Problemática Científica del Derecho. Editorial Losada, S.A. Buenos Aires. 1946. Trad. Jorge G. TeJerInA. 
Kelsen, Hans. TGDE Teoría General del Derecho y del Estado. Imprenta Universitaria. México. 1949. Trad. Eduardo García MAYNEZ.

Kelsen, Hans. D Derogation en Essays in Legal and Moral Philosophy editados por Ota Weinberger. D. Reidel Publishing Company. 1973.

Kelsen, Hans. TPD2 Teoría Pura del Derecho. UNAM. México. 1979. Trad. Roberto J. Vernengo.

Kelsen, Hans. QAJ ¿Qué es un Acto Jurídico?. Isonomía. Revista de Teoría y Filosofía del Derecho. No. 4. Abril 1996.

Métall, Rudolf Aládar. HK Hans KelSEN. Vida y Obra. UNAM. 1976. Trad. Javier Esquivel.

Navarro, Pablo. SNDCD "Sistemas Normativos, Derrotabilidad y Conocimiento del Derecho" en Isonomía. Revista de Teoría y Filosofía del Derecho, 13, Octubre 2000.

NAvarro, Pablo y, Jorge. DSNJ “Derrotabilidad y Sistematización de Normas Jurídicas" en Isonomía. Revista de Teoría y Filosofía del Derecho, 13, Octubre 2000.

, Jorge L. y SuCAR, Germán. TD “Las Trampas de la Derrotabilidad. Niveles de Análisis de la Indeterminación del Derecho" en Analisi e Diritto. 1998.

SChmitL, Ulises. RPCDS "Reconstrucción Pragmática del Concepto del Deber Ser (Sollen)" en Teoría del Derecho y Conceptos Dogmáticos. UNAM. 1987.

SCHmill, Ulises. DAAT La Derogación y la Anulación como Modalidades del Ámbito Temporal de Validez de las Normas Jurídicas. Doxa 19. 1996.

Schmill, Ulises. RPTD Reconstrucción Pragmática de la Teoría del Derecho. Editorial Themis. México. 1997.

Schmilt, Ulises. DON "The Dynamic Order of Norms, Empowerment and Related Concepts" en Law and Philosophy 19. 2000.

Snyder, D. Paul. ML Modal Logic and its Applications. Van Nostrand Reinhold Company. New York. 1971. 